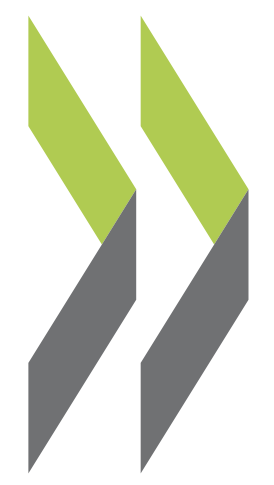

OECD Health Working Papers No. 43

\title{
Measuring Disparities in Health Status and in Access and Use of Health Care in OECD Countries
} Michael de Looper, 
Organisation de Coopération et de Développement Économiques

Organisation for Economic Co-operation and Development

09-Mar-2009

DIRECTORATE FOR EMPLOYMENT, LABOUR AND SOCIAL AFFAIRS

English - Or. English HEALTH COMMITTEE

\section{Health Working Papers}

OECD HEALTH WORKING PAPERS NO. 43

MEASURING DISPARITIES IN HEALTH STATUS AND IN ACCESS AND USE OF HEALTH CARE IN OECD COUNTRIES

Michael de Looper and Gaetan Lafortune

JEL Classification: I10, I18, J10 


\title{
DIRECTORATE FOR EMPLOYMENT, LABOUR AND SOCIAL AFFAIRS
}

\section{OECD HEALTH WORKING PAPERS}

This series is designed to make available to a wider readership health studies prepared for use within the OECD. Authorship is usually collective, but principal writers are named. The papers are generally available only in their original language - English or French - with a summary in the other.

Comment on the series is welcome, and should be sent to the Directorate for Employment, Labour and Social Affairs, 2, rue André-Pascal, 75775 PARIS CEDEX 16, France.

The opinions expressed and arguments employed here are the responsibility of the author(s) and do not necessarily reflect those of the OECD.

\section{Applications for permission to reproduce or translate all or part of this material should be made to:}

\author{
Head of Publications Service \\ OECD \\ 2, rue André-Pascal \\ 75775 Paris, CEDEX 16 \\ France
}

\section{Copyright OECD 2009}




\begin{abstract}
Most OECD countries have endorsed as major policy objectives the reduction of inequalities in health status and the principle of adequate or equal access to health care based on need. These policy objectives require an evidence-based approach to measure progress. This paper assesses the availability and comparability of selected indicators of inequality in health status and in health care access and use across OECD countries, focussing on disparities among socioeconomic groups. These indicators are illustrated using national or cross-national data sources to stratify populations by income, education or occupation level. In each case, people in lower socioeconomic groups tend to have a higher rate of disease, disability and death, use less preventive and specialist health services than expected on the basis of their need, and for certain goods and services may be required to pay a proportionately higher share of their income to do so.
\end{abstract}

Options for future OECD work in measuring health inequalities are provided through suggesting a small set of indicators for development and inclusion in the OECD Health Data database. Some indicators appear to be more advanced for international data collection, since comparable data are already being collected in a routine fashion in most OECD countries. These include the indicators of inequalities in selfrated health, self-rated disability, the extent of public health care coverage and private health insurance coverage, and self-reported unmet medical and dental care needs.

Increased availability and comparability of data will improve the validity of cross-national comparisons of socioeconomic inequalities in health status and health care access and use. Harmonisation of definitions and collection instruments, and the greater use of data linkages in order to allow disaggregation by socioeconomic status, will determine whether health inequalities can be routinely monitored across OECD countries. 


\section{RÉSUMÉ}

Les politiques de santé dans la plupart des pays de l'OCDE ont comme objectifs majeurs la réduction des inégalités en matière de santé et le respect du principe d'un accès adéquat ou égal aux soins basé sur les besoins. Des données robustes et fiables sont nécessaires pour mesurer l'atteinte de ces objectifs politiques. Ce document de travail évalue la disponibilité et la comparabilité de certains indicateurs de l'inégalité de l'état de santé et de l'accès et de l'utilisation des soins dans les pays de l'OCDE, en se concentrant sur les disparités selon les groupes socio-économiques. Ces indicateurs sont illustrés à partir de sources de données nationales ou internationales qui permettent de distinguer les populations par niveau de revenu, d'éducation et d'emploi. Dans tous les cas, les personnes appartenant à des groupes socio-économiques désavantagés ont tendance à avoir des taux de morbidité, d'incapacité et de mortalité plus élevés, à utiliser moins de services préventifs et de soins spécialisés que ce à quoi on pourrait s'attendre sur la base de leurs besoins, et à payer une plus large part de leur revenu pour se procurer certains biens et services de santé.

Parmi les options de travaux futurs de l'OCDE figure le développement d'un petit ensemble d'indicateurs clés dans le domaine des inégalités en santé qui pourraient être intégrés dans la base de données Eco-Santé $O C D E$. Certains indicateurs semblent plus avancés que d'autres pour une collecte de données internationales, puisque des données comparables sont déjà collectées régulièrement dans la plupart des pays de l'OCDE. Ces indicateurs comprennent les indicateurs d'inégalité dans l'état de santé général perçu, l'incapacité auto-déclarée, le degré de couverture des soins de santé publics et de l'assurance maladie privée, et les besoins de soins médicaux et dentaires non satisfaits.

Accroître la disponibilité et la comparabilité des données améliorerait la validité des comparaisons internationales des inégalités socio-économiques de l'état de santé et de l'accès et de l'utilisation des soins. Pour que l'évolution de ces inégalités soit mesurée de manière régulière dans les pays de l'OCDE, il faudra harmoniser les définitions et les méthodes de collecte de données entre pays, et développer les possibilités de lier différentes sources de données au niveau national afin de permettre une désagrégation selon le statut socio-économique. 
TABLE OF CONTENTS

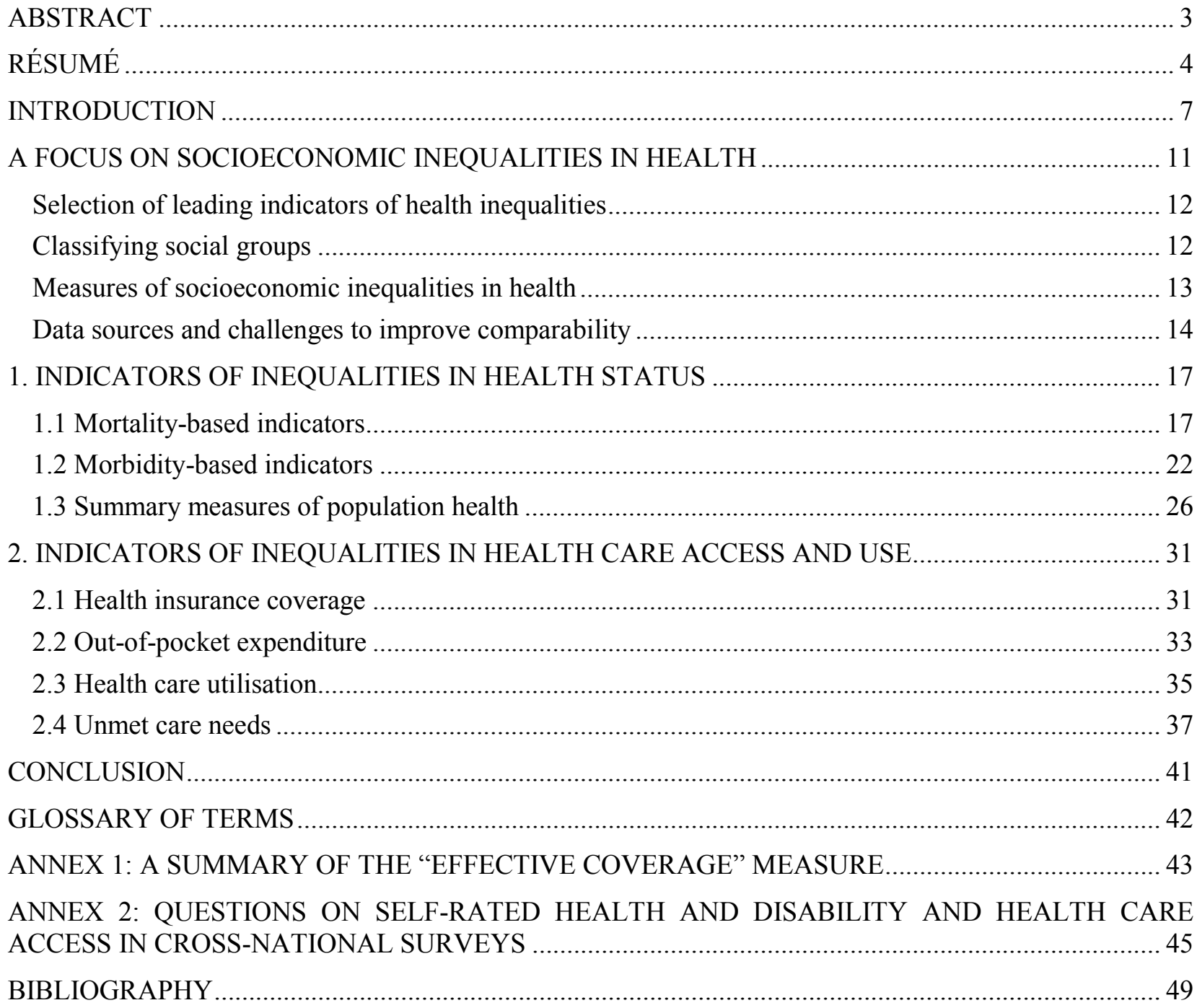

\section{Tables}

Table 1: Data requirements to measure leading indicators of socioeconomic inequalities in health .......... 9

Table 2: Inequalities in fair/poor health in 6 countries, by socioeconomic position................................ 25

Table 3: Self-reported disability status by household income, persons aged 15 years and over, Australia, 2003.

Table 4: Care utilisation by level of education, persons aged over 25, The Netherlands, 2001 ............. 36

Table 5: Proportion of adults reporting unmet needs for dental examination, by income quintile, selected EU countries, 2006. 


\section{DELSA/HEA/WD/HWP(2009)2}

\section{Figures}

Figure 1: Relative and absolute differences in socioeconomic health inequalities ............................... 14

Figure 2: Occupational group differences in life expectancy, England and Wales, 2002-2005.............. 18

Figure 3: Income differences in male life expectancy at age 40 in Germany, the UK and the US.......... 18

Figure 4: Trends in male and female life expectancy at age 20 , by educational attainment, Russian

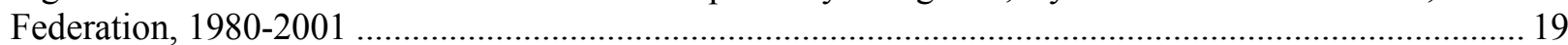

Figure 5: Ratio of total mortality rates between less and more educated people, selected EU countries,

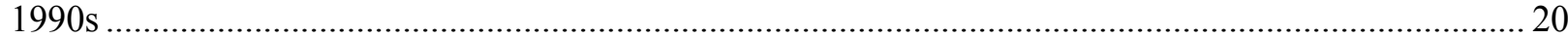

Figure 6: Mortality rate ratios by highest level of education, Korean men aged 30-59, 1990-1991 to

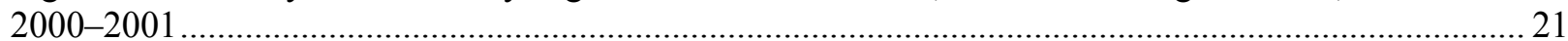

Figure 7: Infant mortality rates by quintiles of wealth, Canada, 1971-1996 ....................................... 22

Figure 8: Percentage of people reporting poor health, by education and gender, Nordic countries, 20002002 .

Figure 9: Inequalities in persons reporting their health as 'very bad', by income quintile and rate ratio,

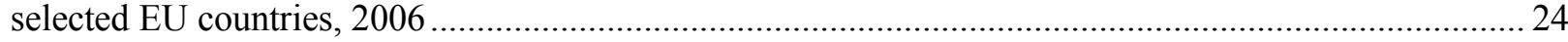

Figure 10: LE and DFLE at birth by deprivation deciles, females, England, 1996-1999 …................... 28

Figure 11: HALE by sex and income level, at birth and age 65, Canada, 2001..................................... 29

Figure 12: DALY rates by socioeconomic quintile, age standardised, Australia, 2003 ......................... 30

Figure 13: Health insurance coverage for a core set of services, 2006 (or latest year available).............. 32

Figure 14: Persons aged less than 65 years with health insurance, by income, US, 1999-2005 .............. 33

Figure 15: Horizontal inequity indices for specialist care use in 17 countries, 2000 or nearest available

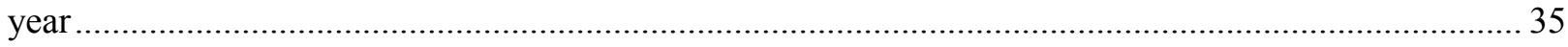

Figure 16: Persons reporting an unmet care need due to costs in 7 countries, by income group, 2007 .... 38

Figure 17: Persons reporting an unmet need for a medical examination because of problems of access, by

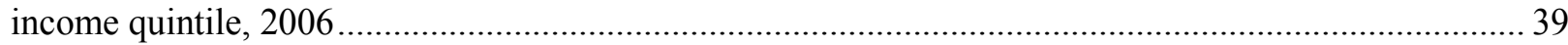

Figure 18: Effective coverage for health interventions, by wealth quintile, Mexico, 2005-06 ................ 44 


\section{INTRODUCTION}

1. There have been substantial improvements in average levels of health outcomes in developed countries over the past 50 years as demonstrated by the health status indicators in OECD Health Data, and as summarised in Health at a Glance 2007. Life expectancy at birth has increased on average in OECD countries from 68.5 years in 1960 to 78.6 years in 2005, infant mortality has declined from 29 deaths per 1000 live births in 1970 to 5 in 2005, and ischaemic heart disease mortality rates have fallen from 178 per 100000 population in 1980 to 96 in 2004. Premature mortality - years of life lost before age 70 - has been cut by more than half on average since 1970 (OECD, 2007a).

2. Differences in health continue to exist among populations, despite the gains of the past half century. These health differences are apparent along many dimensions including age, gender, race or ethnic group, geographic area and socioeconomic status. These differences, also known as variations or differentials in health, are here referred to as health inequalities or disparities. Health inequalities which are avoidable and are considered to be "unfair" according to some social norm which may vary across countries, are here termed health inequities (Kawachi et al., 2002).

3. Health inequality is a global issue, involving rich and poor countries alike. The importance of health inequalities and their determinants, along with the unfairness and avoidability of health inequities, has recently been underlined by the release of the Final Report of the World Health Organization's Commission on Social Determinants of Health (CSDH, 2008). Central to the Commission's work was examining how health is distributed across the social spectrum and how the social conditions in which people grow, live, work and age determine health. The Commission has emphasised that social determinants of health produce widespread inequalities in health within and between societies. These inequalities can be measured and described, and the evidence from this process can be used in producing policies and programmes for change.

4. The growing research interest in health inequalities has required an evidence base to be developed, so that these inequalities can be better understood. Recent work on developing this evidence base has followed two broad strands. The first examines social and economic determinants of health and health inequalities among different groups in society, often defined by income, education, occupation or some other measure of socioeconomic status. The second strand deals with low or differential use of health services among different economic or other groups (Gwatkin, 2007). These two strands are explored in this paper.

5. The objective of this paper is twofold. First, to review the availability and comparability of leading indicators of socioeconomic inequalities in health status and in health care access and use in OECD countries, illustrated by examples using existing data. Second, to outline the steps required to improve the availability and comparability of these leading indicators, in order to promote regular monitoring of progress toward policy goals of reducing health inequalities and providing adequate or equal access to care. ${ }^{1}$

1 No indicators of socioeconomic disparities in health care quality are proposed in this paper, since the development of a reliable and comparable set of health care quality indicators is still at an early stage under the 


\section{DELSA/HEA/WD/HWP(2009)2}

6. Table 1 summarises leading indicators that can be used to measure socioeconomic inequalities in health within the two domains of health status and health care access and use, and indicates in broad terms the data developmental work needed to improve the availability and comparability of data across OECD countries. The paper expands on this summary by giving examples of how these indicators have been used in research. Data availability and constraints are discussed in further detail, and conclusions are drawn on the steps required in order to be able to collect such data in a comparable manner across OECD countries.

OECD's Health Care Quality Indicators (HCQI) project. Regarding inequalities in non-medical determinants of health, the OECD Economics of Prevention project has begun to collect data on a number of determinants of health (overweight and obesity, physical activity and nutrition) by level of education and other aspects of socio-economic status, which may lead to an eventual extension of the regular OECD data collection for those determinants that will be assessed as being most available and comparable across countries (OECD, 2009). Regarding inequalities in health care financing, one relevant indicator is included in this paper - out-of-pocket expenditure by income group. Determining progressivity in other types of financing mechanisms (general taxation, social security contributions, and private health insurance) falls outside the scope of this paper. 
Table 1: Data requirements to measure leading indicators of socioeconomic inequalities in health ${ }^{(a)}$

\begin{tabular}{|c|c|c|c|}
\hline Indicator & Main data sources & $\begin{array}{c}\text { Feasibility and } \\
\text { frequency of } \\
\text { international data } \\
\text { collection }^{(\mathbf{b})}\end{array}$ & $\begin{array}{l}\text { Main areas to improve, and } \\
\text { measurement issues }\end{array}$ \\
\hline \multicolumn{4}{|l|}{ 1. Inequalities in health status } \\
\hline \multicolumn{4}{|l|}{ 1.1 Mortality-based indicators } \\
\hline Life expectancy by SES & Death registries & Feasible, Periodic & $\begin{array}{c}\text { Requires linkage with information } \\
\text { source on socioeconomic status (e.g., a } \\
\text { census) }\end{array}$ \\
\hline Total mortality rate by SES & Death registries & Feasible, Periodic & Idem \\
\hline Infant mortality rate by SES & Death registries & Feasible, Periodic & Idem \\
\hline \multicolumn{4}{|l|}{ 1.2 Morbidity-based indicators } \\
\hline Self-rated health by SES & Survey of health & Feasible, Routine & $\begin{array}{c}\text { Standard survey question(s) } \\
\text { Common perceptions of health among } \\
\text { SES groups within the country }\end{array}$ \\
\hline Self-rated disability by SES & Survey of health & Feasible, Routine & $\begin{array}{l}\text { Standard survey question(s) } \\
\text { Common perceptions of health among } \\
\text { SES groups within the country }\end{array}$ \\
\hline \multicolumn{4}{|c|}{ 1.3 Summary measures of population health } \\
\hline $\begin{array}{l}\text { Disability Free Life Expectancy } \\
\text { (DFLE) by SES }\end{array}$ & $\begin{array}{l}\text { Death registries } \\
\text { Survey of health }\end{array}$ & Less feasible, Periodic & $\begin{array}{l}\text { Combining issues related to measuring } \\
\text { life expectancy by SES and self-rated } \\
\text { disability by SES } \\
\text { Standard survey questions }\end{array}$ \\
\hline $\begin{array}{l}\text { Health Adjusted Life Expectancy } \\
\text { (HALE) by SES }\end{array}$ & $\begin{array}{l}\text { Death registries } \\
\text { Survey of health } \\
\text { Survey or other } \\
\text { method to value } \\
\text { health conditions }\end{array}$ & Less feasible, Periodic & $\begin{array}{l}\text { Combining issues related to measuring } \\
\text { life expectancy by SES and self-rated } \\
\text { health/disability by SES } \\
\text { Common valuing of health conditions }\end{array}$ \\
\hline $\begin{array}{l}\text { Disability Adjusted Life Years } \\
\text { (DALY) by SES }\end{array}$ & $\begin{array}{l}\text { Death registries } \\
\text { Survey of health or } \\
\text { disease registries or } \\
\text { hospital/medical } \\
\text { records } \\
\text { Survey or other } \\
\text { method to value } \\
\text { health conditions }\end{array}$ & Less feasible, Periodic & $\begin{array}{l}\text { Mortality rate by SES (data linkages) } \\
\text { Refinement of disease incidence } \\
\text { measurement } \\
\text { Standard disease weightings } \\
\text { Common valuing of health conditions }\end{array}$ \\
\hline
\end{tabular}


DELSA/HEA/WD/HWP(2009)2

\begin{tabular}{|c|c|c|c|}
\hline Indicator & Main data sources & $\begin{array}{l}\text { Feasibility and } \\
\text { frequency of } \\
\text { international data } \\
\text { collection }^{(b)}\end{array}$ & $\begin{array}{l}\text { Main areas to improve, and } \\
\text { measurement issues }\end{array}$ \\
\hline \multicolumn{4}{|c|}{ 2. Inequalities in health care access and use } \\
\hline $\begin{array}{l}2.1 \text { Population without health } \\
\text { insurance coverage by income } \\
\text { group }\end{array}$ & $\begin{array}{c}\text { Survey or } \\
\text { Administrative data }\end{array}$ & Feasible, Periodic & $\begin{array}{l}\text { Disaggregation by income group } \\
\text { Boundary between public and private } \\
\text { coverage }\end{array}$ \\
\hline $\begin{array}{l}2.2 \text { Health service use by SES } \\
\text { (doctor visits, screening rates, } \\
\text { hospital utilisation, dental care, } \\
\text { etc.) }\end{array}$ & $\begin{array}{c}\text { Survey or } \\
\text { Administrative data }\end{array}$ & Feasible, Periodic & $\begin{array}{l}\text { Standard survey questions, or standard } \\
\text { collection of relevant demographic } \\
\text { information in administrative sources } \\
\text { (e.g., area of residence) } \\
\text { Adjustment for health 'needs' }\end{array}$ \\
\hline $\begin{array}{l}2.3 \text { Unmet medical/dental care } \\
\text { need by income group }\end{array}$ & Survey & Feasible, Routine & Standard survey questions \\
\hline $\begin{array}{l}2.4 \text { Out-of-pocket expenditure as } \\
\text { a share of household income by } \\
\text { income group }\end{array}$ & $\begin{array}{l}\text { Survey or } \\
\text { Administrative } \\
\text { financial data }\end{array}$ & Feasible, Periodic & Disaggregation by income group \\
\hline
\end{tabular}

(a) Each of these indicators requires that the population be classified by level of socioeconomic status (SES). This is most commonly done using information on income level, highest education level or occupational group. SES information is generally sourced from health surveys or censuses, and it requires standard classifications and survey questions to enable meaningful crosscountry comparisons.

(b) Feasible / Less feasible - the feasibility of international data collection. This is based on whether, in most OECD countries, data are currently being collected or will become available soon, whether data collection instruments are harmonised across countries, and whether linkage between different data collections is required.

Routine / Periodic - how frequent international data collection might be; whether the indicator is best suited for routine data collection (annual or biennial), or for periodic collection (every 3-5 years). 


\section{A FOCUS ON SOCIOECONOMIC INEQUALITIES IN HEALTH}

7. Health inequalities exist along many demographic or social dimensions, including sex, age, racial and ethnic group, geographic area and socioeconomic status. The usual starting point in measuring health inequalities is to examine variations by sex and age, and OECD Health Data already reports these for several health status measures. It indicates, for instance, that while a substantial gap in life expectancy remains between men and women, the gap has narrowed in most OECD countries over the past twenty-five years (OECD, 2007a). Mortality data also indicate that the distribution of ages at death among both men and women varies widely across OECD countries (OECD, 2007b). As a next step, the focus is to review the availability and comparability of measures of health disparities by socioeconomic status, including their interactions with sex and age.

8. In almost all countries and in different health systems, a socioeconomic gradient in health status exists. As socioeconomic disadvantage increases, the circumstances in which people live and work are more detrimental, there is an increase in the behaviours which worsen risks and so worsen health outcomes, and an accompanying increase in morbidity and mortality. Populations may be divided into groups characterised by social stratification, with individuals occupying higher or lower levels on a hierarchy - their position on this hierarchy being their socioeconomic status (SES). Persons of lower SES - typically those with a lower income, a lower level of education, or in a less prestigious occupational group - tend to have a higher prevalence of illness and disease, can expect to live less years in good health, have higher mortality rates and die at younger ages. The health burden attributable to socioeconomic disadvantage is large.

9. Socioeconomic inequalities are evident not only in population health status, but also in the access to, and use of health care services. Poorer or less educated persons, despite having higher rates of illness, disease and death, often have difficulties in locating appropriate specialist and preventive health services, they use these services less, and for certain goods and services they may be required to pay a proportionately higher share of their income to do so.

10. Socioeconomic inequalities in health have been observed among different SES groups both within and between countries, regardless of affluence or political or social systems. These inequalities have not diminished in recent decades and in some cases have widened. This finding implies that inequalities are deeply entrenched within the social structures of modern societies, and it provides a warning that reductions in health disparities might be difficult to achieve in the short term (Mackenbach, 2006; Mackenbach et al., 2007).

11. Most national administrations have developed public policies and strategies to reduce socioeconomic inequalities in health status (e.g. Acheson et al., 1998; Department of Health, 2003; AHRQ, 2008; Judge et al., 2006; Mackenbach \& EUROTHINE, 2007). Attempts to quantify the economic impact of health inequalities have pointed to substantial gains that might be made through their reduction (Walker, 2005; Mackenbach et al., 2007). Many OECD countries have also endorsed as a major policy objective the principle that access and use of health care should be based on need, and not the ability to pay (OECD, 2004a). Each of these policy objectives requires an evidence-based approach to measure progress.

12. Identifying and measuring the burden of ill-health in socially disadvantaged sections of the population provides great potential for improving the average health status of the whole population. Cross- 


\section{DELSA/HEA/WD/HWP(2009)2}

country comparisons of socioeconomic inequalities in health status, and in the access and use of health services can suggest areas for improvement for health administrations, and can provide possible policy directions that aim at their reduction. The information gained from the measurement of inequalities gives an impetus and focus for policy makers, as well as a yardstick by which to assess interventions and gauge progress.

13. For these reasons, the focus in this paper is on examining inequalities in health by socioeconomic status. The universal prevalence of socioeconomic inequalities in health, and the importance of education, income and occupation as determinants of health, makes a strong case for selection. This does not negate the importance of other dimensions that are used to examine inequalities in health, such as geographic area or race and ethnicity. In a number of OECD countries, racial and ethnic disparities in health remain a great challenge (Kawachi et al., 2005; Mead et al., 2008). Health differences by geographic area, especially with respect to access to care in remote areas, are also an important policy concern in many countries. A recent OECD publication has reviewed a number of measures adopted in OECD countries to increase the supply of doctors in remote and underserved areas (OECD, 2008).

\section{Selection of leading indicators of health inequalities}

14. Table 1 presented a set of leading indicators that might be used to measure different socioeconomic inequalities in health status, and in health care access and use. The selection of these indicators has been based mainly on the criteria of relevancy, interpretability and feasibility (assessed in terms of data availability and comparability).

15. Indicators for measuring inequalities in health status have been grouped into three categories: (i) indicators related to life expectancy and mortality, (ii) indicators related to morbidity and disability, and (iii) composite indicators which include both mortality and morbidity information.

16. Indicators for measuring inequalities in health care access and use here include: (i) health insurance coverage, (ii) health care utilisation in relation to different services, (iii) measures of unmet care needs, and (iv) out-of-pocket expenditure as a share of household income. A further indicator of 'effective coverage of interventions', which was suggested recently as part of the refinement of the WHO framework for health system performance assessment and which has been tested at the state level in Mexico, is discussed in Annex 1.

\section{Classifying social groups}

17. Socioeconomic status, the hierarchy used here to classify or stratify social groups, can be ordered in numerous ways. The most common of these are by using educational level, occupational group and income level or wealth. Indices comprised of more than one measure of SES may also be used. ${ }^{2}$ A number of international classifications of these stratifiers of SES can be used to facilitate cross-national comparison.

- Educational level is typically measured by a hierarchical classification of the population by completed education. Under the International Standard Classification of Education (ISCED) at least four categories are identified, corresponding to elementary, lower secondary, upper

2 Area-based indices, for example, are constructed from weighted variables collected through a census or other survey, and allow for comparisons of social and economic conditions across a country. Persons living in areas with lower scores are then associated with a lower average SES. The variables used differ across countries, so the indices cannot be used for cross-country comparison. Examples include the Socioeconomic Indexes for Areas (SEIFA), used in Australia, and the Socioeconomic Risk Index (SERI), used in Canada. 
secondary and tertiary. Part-time and vocational training are also included, but are difficult to fit into the hierarchy.

- Occupation information is used to divide the population into a number of groups, with distinctions often made between farmers, unskilled and skilled manual groups, self-employed, and lower and upper non-manual groups. The International Standard Classification of Occupations (ISCO) can be used to identify more specific categories of occupation. A person's occupational group may vary throughout their working life, but it is usually determined by the individual's current or last occupation.

- Income level can be classified according to individual income, or by the household equivalent income - household income adjusted for size and composition, i.e. numbers of adults and children. The entire population may then be classified into a number of groups of equal frequency for analysis (e.g. five-groups: quintiles, or ten-groups: deciles). Income level may also be analysed by using national poverty lines in order to determine SES.

\section{Measures of socioeconomic inequalities in health}

18. There are many measures of socioeconomic inequalities in health, and they vary in complexity. These measures differ in at least two ways: (i) whether they measure relative or absolute differences in health, and (ii) whether the measurement technique is simple or sophisticated (Mackenbach \& Kunst, 1997). The choice of which is most appropriate depends largely on the objectives of the particular study being undertaken.

19. Relative or absolute differences - Measurement can be expressed as a relative difference (for example, a rate ratio) or an absolute difference (for example, a difference in rates). Both are important, as the theoretical example in Figure 1 illustrates. Assume two population groups A and B that have seen large falls in mortality rates between two reference years 1970 and 2000, with the gap between the two also narrowing. In 1970, the gap was 30 deaths per 100000 population, coming down to only 10 in 2000 . The ratio of deaths per 100000 population between groups A and B has increased from two in 1970 (60/30) to three in $2000(15 / 5)$. The mortality rate of both groups has improved and the absolute gap between them has narrowed, however Group A's relative position has not improved; and in 2000 it was worse. The illustration highlights that to gain a better understanding of the health status of the two groups, both measurements should be considered. Absolute measures are important for decision-makers, especially when goals in absolute terms have been set, because they allow a better appraisal of the magnitude of a public health problem (Schneider et al., 2004). 
Figure 1: Relative and absolute differences in socioeconomic health inequalities

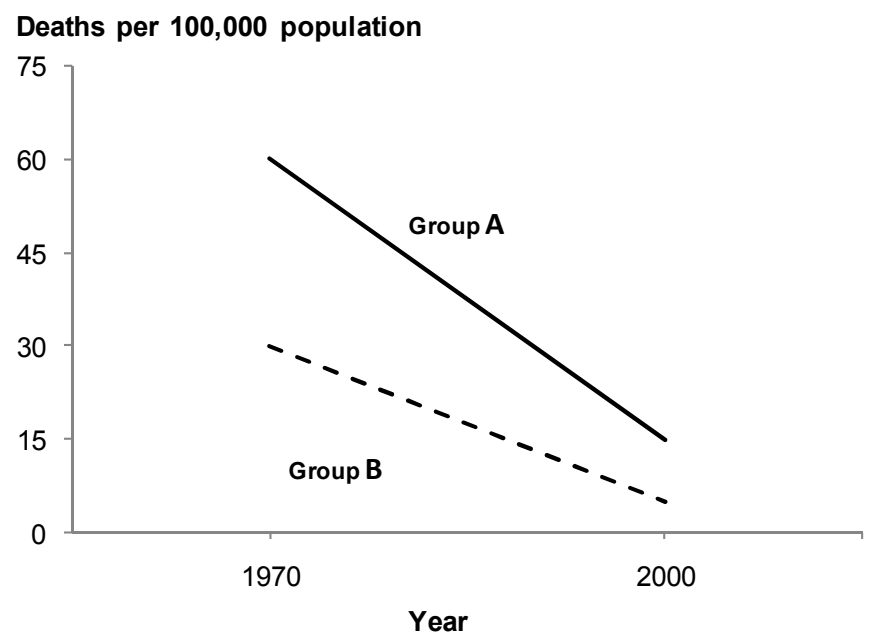

20. Simple or sophisticated measures - Simple measures of inequality such as the rate difference and the rate ratio between lower and higher socioeconomic groups allow for ease of calculation and interpretation. These measures of the 'gap' between two population groups generally only considers health inequalities between the two extreme groups, such as the highest and lowest income groups equivalent to quintiles 1 and 5 if a population is divided into five equal groups. Gap measures emphasise the situation of the most deprived group. The measures are often used for routine data collection and for monitoring over longer time periods. However, they ignore information on the large proportion of the population that falls in between, in quintiles 2, 3 and 4 .

21. A second group of more sophisticated regression-based measures summarise the magnitude of inequalities across all population groups. These include summary indices such as the relative index of inequality, and the concentration index, which is calculated in a similar fashion to the Lorenz curve and Gini coefficient (Wagstaff et al., 1991; Mackenbach \& Kunst, 1997; Schneider et al., 2004; Harper \& Lynch, 2005). These measures include information on both the magnitude of inequality and the total population distribution of inequality, but at the expense of ease of interpretation and with greater restrictions on the types of data which can be used. They often require that socioeconomic status be measured on a quantifiable scale, and this might prove problematic for education- and occupation-based indicators.

22. An important consideration in choosing an appropriate measure of health inequality is the ease in which they allow for routine data updating and ongoing monitoring. The choice of health inequality measure is guided by restrictions imposed by available national or cross-national data, the requirements for regular data provision and the assembling of a time series, the ease of interpretability and the resources available for calculation of the indicator. Simpler measures such as rate ratios and rate differences would be more feasible for a regular data collection such as the one carried out under OECD Health Data. In using these simple measures, due care should be taken to present as much contextual information as possible, such as providing both relative and absolute differences.

\section{Data sources and challenges to improve comparability}

23. Data sources used to monitor socioeconomic inequalities in health should be nationally representative, and must contain individual-level information which can be combined to form groups of 
similar socioeconomic status. Data should contain measures of age, sex, SES and health status or health care access and use. To ensure robust cross-national comparisons, each of these measures must be collected in a standard fashion across all countries. Some common data sources that are used include vital statistics collections such as mortality registries, censuses, population-based surveys and health or social security records (see Table 1).

24. National mortality registries provide information on deaths by sex, age and cause, but in most countries registries collect little or no information that can be used to determine socioeconomic status. This means that data linkages need to be made between mortality registries and other comprehensive information sources on the population (such as censuses), so as to be able to classify indicators of mortality or life expectancy by some measure of socioeconomic status. In practice this only occurs in some countries, and it is generally not undertaken for routine monitoring purposes.

25. National health sector information such as hospital admission records rarely include information on income, education, occupation or other socioeconomic measures. If place of residence is collected, this can be used to assign individuals to an area-based SES measure. Information derived from these sources usually needs to be linked to another source which provides information on SES.

26. Health surveys are particularly well-suited to national-level analyses of inequalities in health status (especially morbidity/disability) and in health care access and use. However, gathering comparable data at an international level is limited by variations in the questions used to measure either health status, or health care access and use, or socioeconomic status (see Annex 2). Limitations are also imposed by differences in survey methodologies such as the reference population used and the mode of survey administration. Further efforts to harmonise survey questions on health status, health care access and use, and socioeconomic variables are required in order to improve the comparability of the data used to measure socioeconomic inequalities in health.

27. In Europe, cross-national health interview surveys (or health modules in broader surveys) provide information on self-assessed health and disability, as well as on health care use and unmet care needs based on a common set of questions. These surveys include:

- European Union Statistics on Income and Living Conditions (EU-SILC) - covers the entire adult population aged 16 years and over in countries surveyed, except the population in institutions. The survey contains questions that can be used to examine inequalities in four areas: self-rated general health, chronic illnesses or conditions, activity limitation (disability) and unmet need for medical or dental examination or treatment. Information is also collected on education and income, allowing population stratification by SES. The survey is conducted annually. Data are currently available for 15 European countries for the year 2004, and 27 countries for 2005 and 2006. Data tables are available at the Eurostat website (www.epp.eurostat.ec.europa.eu). ${ }^{3}$

3 EU-SILC is the successor to the European Community Household Panel (ECHP), which was a panel survey conducted annually in most EU countries from 1994 to 2001. ECHP included a small number of health-related questions covering self-rated health, chronic illness and activity limitation, the use of health and dental services, and health risk factors, along with information on education and income level. 


\section{DELSA/HEA/WD/HWP(2009)2}

- $\quad$ European Health Interview Survey (EHIS) - Eurostat has developed a number of modules to measure a wide variety of indicators of health status, health care use and socioeconomic status in a harmonised way. European Union countries are being encouraged to periodically (once every five years) implement these modules in their national surveys. About two-thirds of the $27 \mathrm{EU}$ countries have committed to implement the survey between 2006 and 2010. The EHIS holds potential for future analysis of health inequalities by socioeconomic status. ${ }^{4}$

- Survey of Health, Ageing and Retirement in Europe (SHARE) - covers populations aged 50 and over, excluding the population in institutions, and contains questions on physical health, behavioural risks, cognitive function, mental health and health care, as well as on income, education and occupation. Eleven countries contributed to the 2004 baseline study, with 15 participating in a second wave of data collection in 2006-07, and 16 due to participate in the third wave in 2008-09. This survey is similar in many ways to the US Health and Retirement Survey (HRS). Information is available at www.share-project.org.

28. Beyond Europe, one of the main cross-national surveys that has been used to collect information on socioeconomic inequalities in health is the Commonwealth Fund International Health Policy Survey. This survey is conducted annually by the Commonwealth Fund, and it has been used to carry out similar analyses among the non-European and European OECD countries covered - seven in 2007, including Australia, Canada, Germany, the Netherlands, New Zealand, the United Kingdom and the United States (Schoen et al., 2007). The survey contains questions on unmet health care needs and access problems, and results from the 2001 and 2004 surveys were published with an analysis by respondent income (www.commonwealthfund.org). The 2002-03 Joint Canada/United States Survey of Health is another survey that has been used to measure and compare socioeconomic disparities in health status, health care use and unmet care needs between these two countries (Sanmartin et al., 2004).

The Eurostat website also contains data from national health interview surveys that were carried out between 1999 and 2003 in most EU Member States and which were harmonised to the extents possible. The data include survey results regarding questions on self-rated health, longstanding illness and disability (activity restriction), health service use and preventative screening, stratified by educational level (www.epp.eurostat.ec.europa.eu). 


\section{INDICATORS OF INEQUALITIES IN HEALTH STATUS}

29. Kunst and Mackenbach (1995) have defined socioeconomic inequalities in health status as

"Differences in the prevalence or incidence of health problems between individual people of higher or lower socioeconomic status"

30. In using this definition it should be emphasised that although individuals are referred to, analyses of socioeconomic inequalities in health usually consider groups of individuals, linked by a common SES. Within such a group, the individuals comprising it will differ in their health status; however taken as a whole, people with lower SES tend to have higher morbidity and mortality rates.

\subsection{Mortality-based indicators}

31. Indicators such as life expectancy, cause-specific and total mortality rates and infant mortality are commonly used to monitor population health status. Data by sex and age are widely available and relatively precise, but data linked to other measures of SES are scarcer.

\section{Life expectancy}

32. Life expectancy is a measure of how long a person might expect to live if the mortality patterns occurring in a particular year remained unchanged over a lifetime. Life expectancy measures the length of life, but not its quality. The measures are derived from life tables, which are commonly calculated using mortality data held in registries, although surveys and censuses may also be used. To calculate life expectancies for different socioeconomic groups, mortality data for individuals must be 'linked' to another data set which includes information on the individuals' SES, such as a census.

33. In 2006, Eurostat established a Task Force to develop indicators of life expectancy by socioeconomic status for EU countries. The Task Force's preferred approach is to link death certificates with census information. The next census in 2011 provides an opportunity to put in place or refine the statistical systems needed for the production of harmonised mortality data by socio-economic status. However, the requirement for data linkage with census information means that this indicator might not be suited for regular monitoring, since censuses are infrequent. But because life expectancies tend to increase slowly in developed countries, except in certain circumstances, monitoring may only be necessary at 5-yearly intervals or longer.

34. The available evidence shows that life expectancy is shorter among persons from lower socioeconomic groups, reflecting group differences in the risk of dying. A number of studies have observed differences in life expectancy at birth between lowest and highest socio-economic groups, in the order of four to six years among men and two to four years among women, but larger differences may also be observed (Mackenbach, 2006; Singh \& Siahpush, 2006; Public Health Agency of Canada, 2008; Whitehouse \& Zaidi, 2008).

35. Figure 2 provides an illustration of the link between socioeconomic inequality and life expectancy. Men and women working in the least skilled occupations in England and Wales can expect to live seven years less than persons working in professional occupations. The effect is observed not only between the least and most skilled; the social gradient is evident across all levels of society, so that in this example skilled workers have two to three years lower life expectancy than those in professional occupations. 
DELSA/HEA/WD/HWP(2009)2

Figure 2: Occupational group differences in life expectancy, England and Wales, 2002-2005

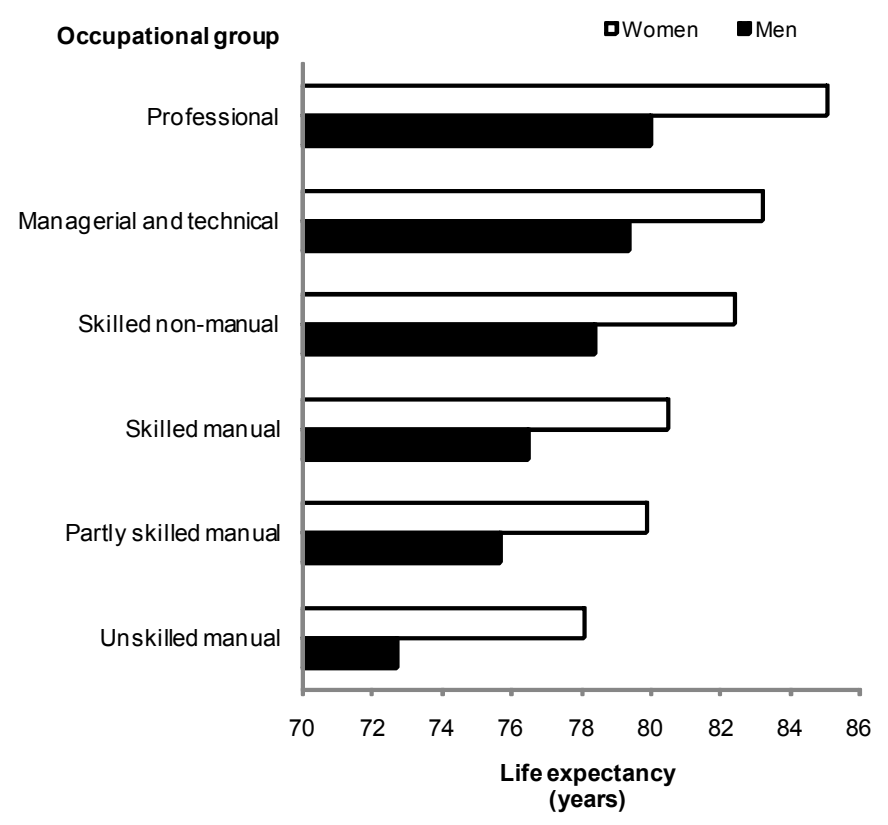

Source: ONS Longitudinal Study, 2007.

36. Figure 3 provides a further example, using income groups. Longitudinal data from household panel surveys conducted in Germany, the United Kingdom, and the United States indicate that average total life expectancy for a 40-year-old low-income male (the lowest third of equivalised net household incomes) is four to five years less than that of high income male (the highest third) (Whitehouse \& Zaidi, 2008).

Figure 3: Income differences in male life expectancy at age 40 in Germany, the UK and the US

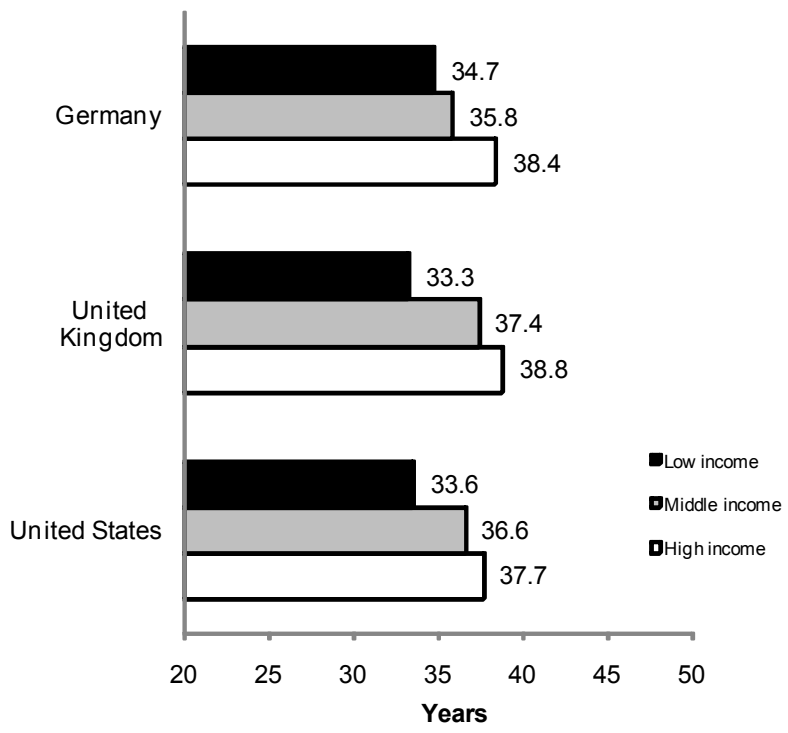

Sources: Whitehouse \& Zaidi, 2008; OECD unpublished. 
37. Analyses stratifying populations by education give the same picture (Figure 4). The life expectancy of better-educated men and women in the Russian Federation increased substantially between 1980 and 2001, while it declined for the least-educated. In 1980, life expectancy at age 20 for universityeducated men was three years greater than for men with elementary education only; by 2001 this difference had increased to 11 years. Similar patterns were seen in women (Murphy et al., 2006). A widening in life expectancy inequalities between those with lower and higher socioeconomic status scores has also been observed in Finland around this time, with differences in deaths from cardiovascular diseases and alcoholrelated conditions together accounting for most of the increase in health inequalities in that country (Mackenbach, 2006).

38. The monitoring of socioeconomic inequalities in life expectancy is part of a Programme for Action for the national health inequalities strategy in England (Department of Health, 2008). A target for life expectancy has been set: by 2010 to reduce the gap between the fifth of areas with the worst health and deprivation indicators and the population as a whole, by at least $10 \%$.

Figure 4: Trends in male and female life expectancy at age 20, by educational attainment, Russian Federation, 1980-2001

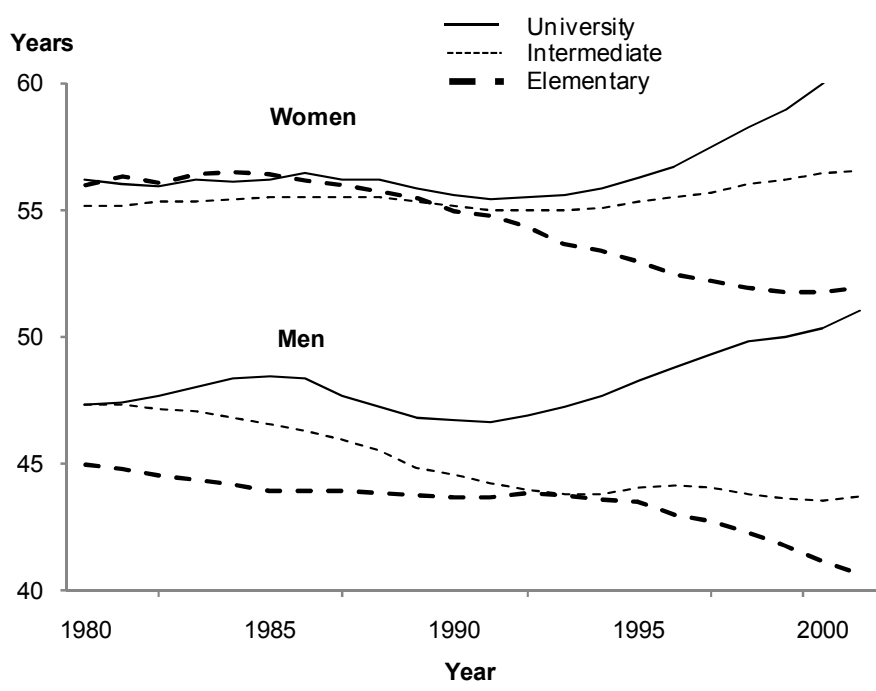

Source: Murphy et al., 2006

\section{Total mortality}

39. Important differences in mortality rates are found between different socioeconomic groups. Rates of mortality are higher among persons with lower levels of education or income, or in lower occupational classes, and these differential rates are evident for most major causes of death. These inequalities in mortality exist across all age groups and both sexes, although they tend to be smaller among women than men (Mackenbach, 2006).

40. Vital statistics registries are the starting point for examining socioeconomic inequalities in mortality. Information on income, education or occupation is needed to stratify populations by SES, and this is usually obtained through linking mortality records to a census or other survey. In some countries, relevant information such as the usual occupation of the deceased is collected following death, and is included on death certificates. This information can be used to stratify populations by SES, if available electronically. 


\section{DELSA/HEA/WD/HWP(2009)2}

41. Measuring SES using levels of income, education or occupation is not straightforward, and due care needs to be taken in ensuring that cross-national comparisons are valid through comparing similar categories. The requirement for data linkage to censuses or other surveys adds difficulty to using this indicator for routine monitoring purposes, since censuses are infrequent.

42. Data on total mortality rate ratios by education, income and occupation are available for most OECD countries, albeit on an irregular basis (see, for example, Mackenbach et al., 2008; Fukuda et al., 2007; Khang et al., 2004). Long time series of mortality data with socioeconomic information covering large national samples are only available for a limited number of countries.

43. Figure 5 presents information on deaths among mostly middle-aged men and women in a number of European countries. Mortality data were linked to censuses carried out during the early-to-mid 1990s in order to obtain information on the highest level of completed education. Age-standardised death rates and rate ratios were calculated for educational groups, with a rate ratio of 1.0 indicating no difference between lower and higher educated persons. Mortality rates among less educated persons are markedly higher. In European countries, less educated persons have a $20-50 \%$ excess risk of dying than more educated persons, and in some countries mortality rates are more than double. Inequalities are larger for men, except in Spain (Mackenbach, 2006).

Figure 5: Ratio of total mortality rates between less and more educated people, selected EU countries, 1990s or nearest available year

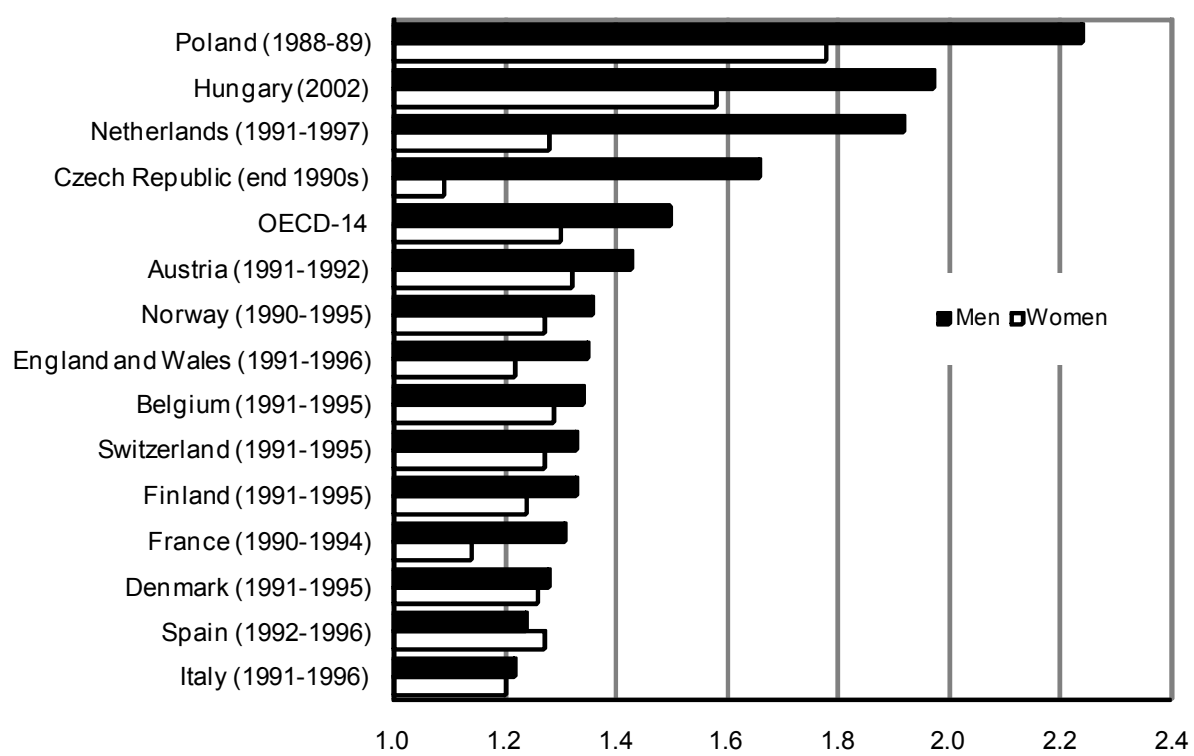

Source: Mackenbach, 2006 
44. A further example from Korea shows inequalities in mortality among men, according to their highest level of completed education (Figure 6). Men with the least education had mortality rates four to five times higher the most educated group. Although mortality rates fell for all groups over the ten-year period 1990-1991 to 2000-2001, the relative level of socioeconomic inequality in mortality appeared to be unchanged (Khang et al., 2004).

Figure 6: Mortality rate ratios by highest level of education, Korean men aged 30-59, 1990-1991 to $2000-2001$

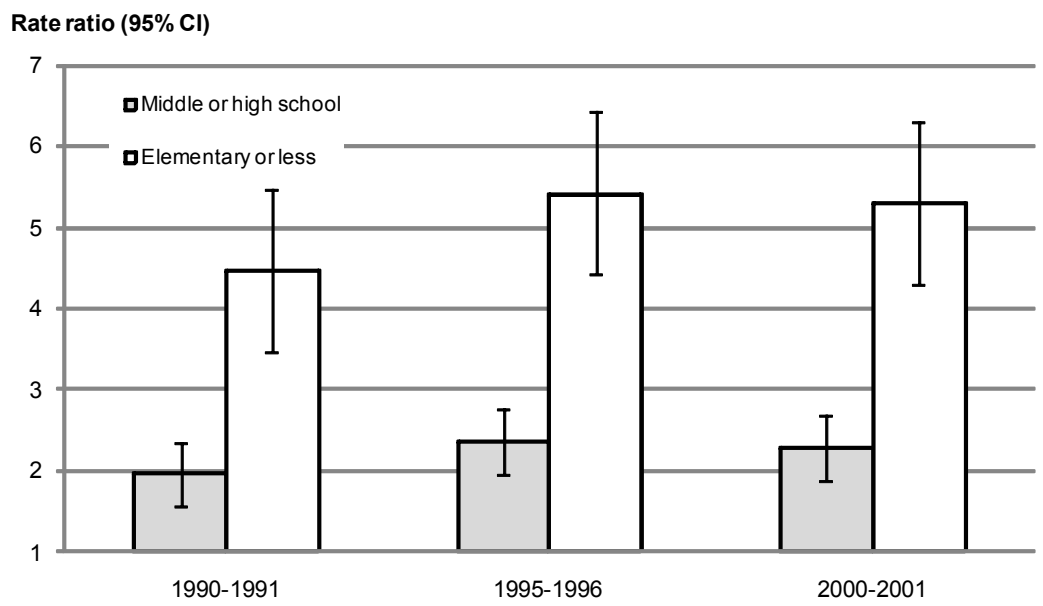

Note: College education or higher $=1.0$.

Source: Khang et al., 2004

\section{Infant mortality}

45. Infant mortality is a frequently-used indicator of population health and social progress. All OECD countries have seen remarkable progress in reducing infant mortality in recent decades, with an average reduction of $80 \%$ across the 30 countries between 1970 and 2005 (OECD, 2007a). Yet widespread inequalities in infant mortality rates persist within countries. Figure 7 provides an illustration, and shows infant mortality rates for urban neighbourhoods in Canada by quintiles of wealth. Rates declined rapidly for all neighbourhoods between 1971 and 1996, although they remain highest among the poorest neighbourhoods. Inequalities narrowed somewhat over the time period, in that the rate ratio of the richest and poorest neighbourhoods (Q1/Q5) declined from 2.0 in 1971 to 1.7 in 1996, although progress slowed after 1991. 
Figure 7: Infant mortality rates by quintiles of wealth, Canada, 1971-1996

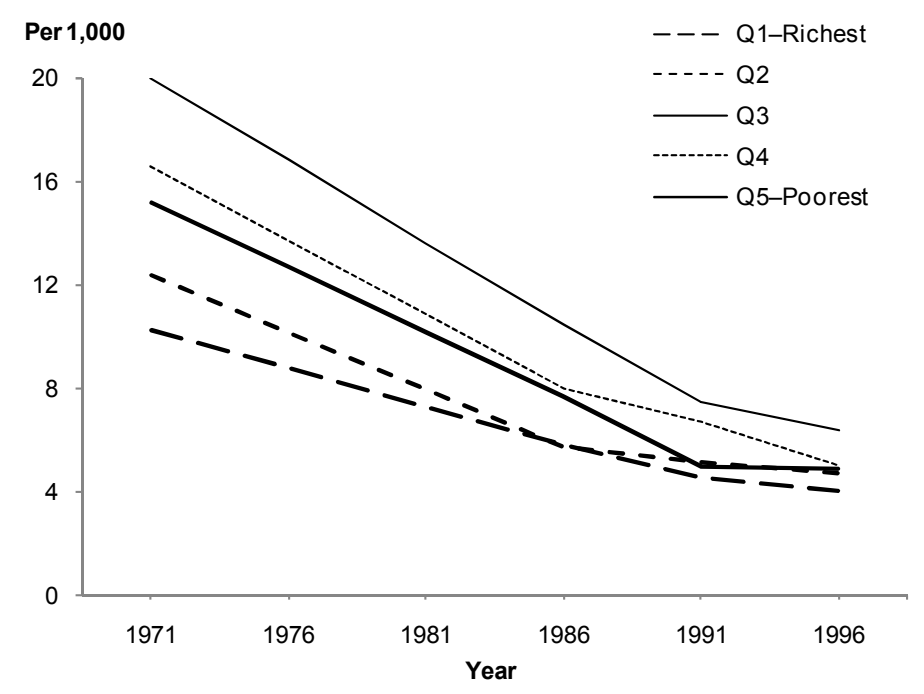

Sources: Wilkins \& Houle, 1999; Wilkins, 2003

46. A similar study examined trends in infant mortality in the United States between 1960 and 2002, by county median family income (Krieger et al., 2008). Infant mortality declined in all county income quintiles, and both absolute and relative inequalities shrank between 1966 and 1980; relative health inequalities widened thereafter, with little change in the magnitude of absolute differences.

47. A number of countries use infant mortality to monitor health inequality targets. The United Kingdom Department of Health target is to reduce the gap in infant mortality in England and Wales between the 'routine and manual' occupation group and the population as a whole to $10 \%$ by 2010 (Department of Health, 2007). The infant mortality rate among the routine and manual group was $17 \%$ higher than the total population in 2004-06, compared with 19\% higher in 2002-04, and $13 \%$ higher in the baseline year 1997-99. While the gap has decreased in recent years, further progress will be needed to reach the $10 \%$ target by 2010 .

48. The same data sources used for the analysis of total or cause-specific mortality allow for the examination of socioeconomic inequalities among particular age groups, including infants. The need for age-standardisation of data is avoided, but the challenge of linking data sources containing information on mortality and SES remains. Determining the SES of an infant is usually through ascertaining the status of a parent, or of the geographic area of residence of the household.

\subsection{Morbidity-based indicators}

49. Other measures beyond those based on mortality are required for monitoring inequalities in population health status. As life expectancy increases and chronic disease prevalence continues to rise, policy makers need additional information on the non-fatal consequences of disease and severity of health conditions. A number of morbidity-based indicators of socioeconomic inequalities in health are available, generally utilising information on self-reported health, illness or activity limitation. 


\section{Self-reported health}

50. Questions on self-reported health form part of most national and cross-national health surveys, and can be used to gauge levels and distributions in population health status. These surveys include a question of the form: "How is your health status in general? Very good, good, fair, bad or very bad". Although subjective in nature, within particular national cultures the measure correlates well with other measures of health status, and it has been found to be useful in predicting future health problems and health service use (Miilunpalo et al., 1997). This question, or more elaborate sets of questions on self-reported health, can also be used in the calculation of healthy life expectancies and other summary measures of health (see next section). It remains one of the most widely available indicators of health inequalities by SES.

51. The main sources of information on self-reported health are national, or cross-national health interview surveys. In European countries, both EU-SILC and EHIS collect information on self-reported health, and the available data allow a stratification of the population either by income or education. In order to promote valid international comparisons, the methods and instruments - including the survey questions, response categories and the populations surveyed - must be standard (see Annex 2). For the purpose of measuring disparities in each country, populations within countries must also share common cultural standards and perceptions of good health. For these reasons, caution is required when making cross-country comparisons using this indicator. A number of cross-national studies of self-reported health by SES are available (Sanmartin et al., 2004; NOMESCO, 2004; Mackenbach, 2006).

52. When self-reported health is analysed by SES groupings, important differentials in population health status are revealed. Among Nordic countries, for example, a series of national surveys conducted in 2000-2002 found that greater proportions of persons with low education report poorer health, and more so in Finland than Sweden, Norway or Denmark (Figure 8). Women tended to report poorer health than men, except in Finland.

Figure 8: Percentage of people reporting poor health, by education and gender, Nordic countries, 2000-2002

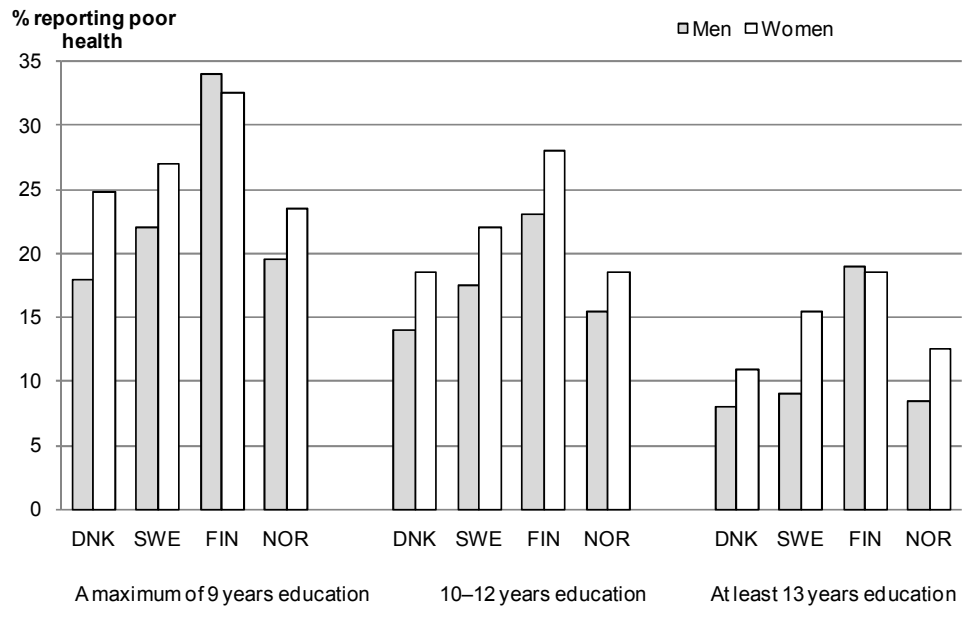

Source: NOMESCO, 2004 


\section{DELSA/HEA/WD/HWP(2009)2}

53. These findings are repeated in many countries - people in lower socioeconomic groups report poorer health. But the extent of inequality varies from country to country, with differing rates of inequality between income groups reporting 'very bad' or 'bad' health, for example (Figure 9). Within EU countries, reported poor health among the population as a whole is most prevalent in Eastern European countries (Hungary, the Czech and Slovak Republics, Poland), along with Portugal and Spain; however, as previously discussed, different populations do not always share common standards and perceptions of good health. Inequalities within countries between low and high income groups are greater in Belgium, Iceland, Ireland and the United Kingdom, although in the latter three countries, the proportion of persons reporting poorer health is low.

Figure 9: Inequalities in persons reporting their health as 'very bad', by income quintile and rate ratio, selected EU countries, 2006
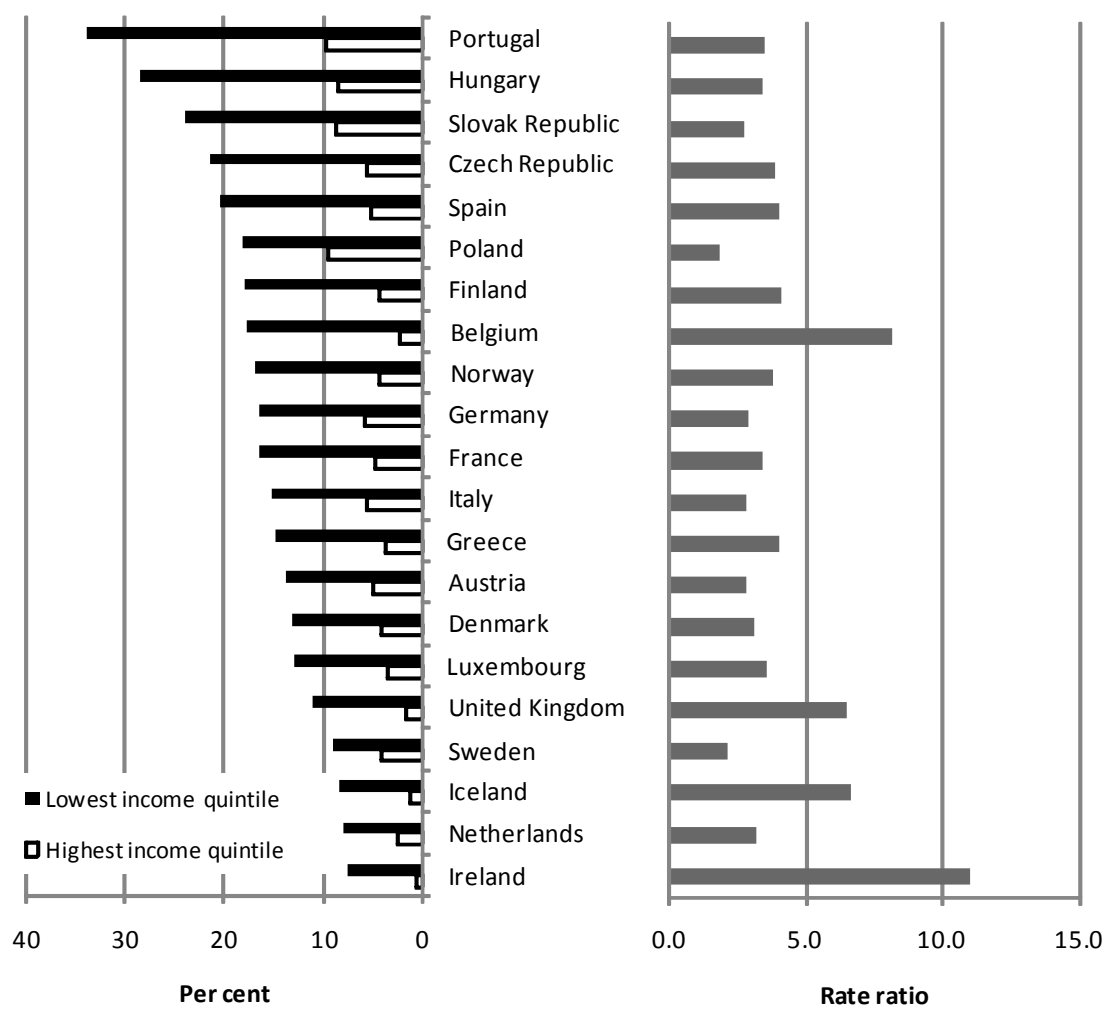

Source: EU-SILC

54. The situation is no different in non-European countries, with numerous studies confirming poorer self-rated health among persons from lower socioeconomic groups. There are differences, however, in the specific measure of SES used in the published data that are readily available, with some countries such as Australia and New Zealand using a Disadvantage or Deprivation Index, while other countries use education or income levels (Table 2). Such differences hamper cross-country comparisons with data derived from EU-SILC.

55. Inequalities in self-reported morbidity are substantial, and persons with lower socio-economic status have higher morbidity rates not only in self-reported health, but also in chronic conditions and disability. The inequalities are persistent, although as yet it is unclear whether gaps are widening over time (Mackenbach, 2006). 
DELSA/HEA/WD/HWP(2009)2

Table 2: Inequalities in fair/poor health in 6 countries, by socioeconomic position

\begin{tabular}{|c|c|c|c|c|c|}
\hline Country & $\begin{array}{l}\text { Indicator of socio- } \\
\text { economic position }\end{array}$ & Period & Age-group & Rate ratio $^{(a)(b)}$ & Source \\
\hline Australia & Disadvantage index & $2004-05$ & $15+$ & 2.20 & National Health Survey \\
\hline Canada & Education & 2005 & $12+$ & 1.60 & $\begin{array}{c}\text { Community Health } \\
\text { Survey }\end{array}$ \\
\hline Japan & Education & $2002-2005$ & $20+$ & 1.42 & $\begin{array}{l}\text { WHO World Mental } \\
\text { Health Survey }\end{array}$ \\
\hline Korea & Education & 1999 & $30-59$ & $\begin{array}{c}2.09(\mathrm{M}) \\
1.81(\mathrm{~F})\end{array}$ & Social Statistics Survey \\
\hline New Zealand ${ }^{(\mathrm{c})}$ & Deprivation index & $2006-07$ & $15+$ & $\begin{array}{l}1.36(\mathrm{M}) \\
1.35(\mathrm{~F})\end{array}$ & National Health Survey \\
\hline United States & Income & 2006 & All ages & 3.33 & $\begin{array}{l}\text { National Health } \\
\text { Interview Survey }\end{array}$ \\
\hline
\end{tabular}

(a) Data collection and classification methods differ between countries, so the magnitude of inequalities cannot be directly compared.

(b) Ratio of odds of fair or poor self-assessed health in lower socio-economic groups as compared to higher groups.

(c) For New Zealand, the ratio is for very good/excellent health.

Sources: ABS, 2007; Public Health Agency of Canada, 2008; Honjo et al., 2006; Khang et al., 2004; NZ MoH, 2008 ; NCHS, 2007.

\section{Self-reported disability}

56. Monitoring disability is important in the light of population ageing and increasing rates of chronic disease. Self-reported disability reflects the non-fatal consequences of disease and impairment, and can provide some indication of the need for medical and social services. Information on self-reported disability may also be used to calculate various measures of healthy life expectancy (see next section).

57. Progress towards a universal concept and definition of disability was assisted by the adoption of the International Classification of Functioning, Disability and Health (ICF) by the World Health Organization in 2001 (WHO, 2001). The ICF uses the term 'disability' to broadly cover any or all of the following components: impairment, activity limitation and participation restriction, as influenced by environmental factors ${ }^{5}$. A number of cross-national initiatives (notably the Budapest Initiative on Health Status Measures, and the UN Washington City Group on Disability Statistics) have in recent years sought to develop a small set of standard questions on health status and disability that could be recommended for use in (cross-) national surveys or censuses.

58. Currently, measures of self-reported disability are available for most OECD countries, although the survey instruments vary across countries, thereby limiting comparability (see Annex 2). In Europe, the EU Statistics on Income and Living Conditions survey (EU-SILC) includes one general question on disability. The health status module in the European Health Interview Survey (EHIS) also recommends that EU countries use this question, along with a more elaborate set of questions, to measure different types of disabilities. Other countries include questions on disability in general health or specialised surveys,

\footnotetext{
5 Impairments are "problems in body function or structure such as significant deviation or loss". Activity limitations are "difficulties an individual may have in executing activities". Participation restrictions are "problems an individual may experience in involvement in life situations". Environmental factors "make up the physical, social and attitudinal environment in which people live and conduct their lives" (WHO, 2001).
} 


\section{DELSA/HEA/WD/HWP(2009)2}

although the question might measure a different type of disability. Additional demographic and other information collected in these surveys allow for stratification of respondents by SES groups.

59. Disability rates tend to be higher among socioeconomically disadvantaged persons. Results from the Australian Bureau of Statistics (ABS) 2003 Survey of Disability, Ageing and Carers, for example, indicate that self-reported disability is three to four times more prevalent in the lowest income quintile, compared with the highest income quintile (Table 3). This finding is related to people in lower socioeconomic groups having higher frequencies of physical and mental health problems.

Table 3: Self-reported disability status ${ }^{(a)}$ by household income, persons aged 15 years and over, Australia, 2003

\begin{tabular}{cc}
\hline Equivalised gross household income quintiles & All reported disabilities (\%) \\
\hline Lowest quintile & 29.4 \\
Second quintile & 19.2 \\
Third quintile & 12.4 \\
Fourth quintile & 9.5 \\
Highest quintile & 8.3 \\
Not applicable or not known & 21.3 \\
Total & 100.0 \\
\hline
\end{tabular}

(a) In this survey a person has a disability if they report that they have a limitation, restriction or impairment, which has lasted, or is likely to last, for at least six months and restricts everyday activities.

Source: ABS, 2004

60. A large body of evidence reports that higher educational levels are associated with lower levels of disability (Mackenbach, 2006; Lafortune et al., 2007). Higher educational levels are often accompanied by higher incomes and standards of living, a lower risk of work-related injury or ill-health, and healthier behaviours such as a balanced diet and a lower prevalence of smoking and risk alcohol drinking. Across 19 OECD countries in the late $1990 \mathrm{~s}$, the average disability prevalence rate among groups with lower educational attainment was 19\%, compared with $11 \%$ among the better educated (OECD, 2003). ${ }^{6}$

\subsection{Summary measures of population health}

61. Increasingly, a variety of health information is needed to complement conventional measures of life expectancy, and to determine whether ageing populations are living longer lives free of disability or ill health. Summary measures of population health assist in this by combining information on both mortality and morbidity, so as to better monitor population health and forecast future health care needs. These measures provide information on the number of remaining years a person might expect to live, and on their health status during those years.

62. Several measures have been developed, each seeking to calculate the average expectation of years of life in equivalent good health, after adjusting for years lived with some form of illness or disability. Summary measures of population health include Disability Free Life Expectancy (DFLE),

6 Based on national surveys, including the European Community Household Panel in European countries. In this survey, respondents who answered 'Yes' to the question 'Do you have any chronic physical or mental health problem, illness or disability?' were then asked 'Are you hampered in your daily activities by this physical or mental health problem, illness or disability', and responded either 'Yes, severely/Yes, to some extent/No'. 
Health Adjusted Life Expectancy (HALE) and Disability Adjusted Life Year (DALY). These measures may also be calculated for different socioeconomic groups within a population.

63. The measures are relatively easy to interpret, being based on recognisable concepts of illness, disability and mortality. Their calculation is more complex, since they rely on at least two data sources - a measure of morbidity or disability, usually a health or household interview survey, and a measure of mortality, often a census cohort linked to a mortality registry. One of these sources must also contain information on socioeconomic status, if summary measures by SES group are to be calculated.

64. Regular monitoring of summary measures of socioeconomic inequalities in health within countries is still uncommon. Cross-national comparisons of summary measures are further complicated by needing to ensure that the concepts and methods used in data sources are standard across countries. In recent years, international organisations such as Eurostat and the World Health Organization have made efforts to improve understandings and applications of concepts and methods, and to harmonise summary measures of population health, although it remains a challenge to disaggregate them by SES.

\section{Disability Free Life Expectancy (DFLE)}

65. The Disability Free Life Expectancy (DFLE) measure aims to quantify the remaining years a person of a certain age can expect to live without disability. The measure requires mortality data as for a standard life table, and estimates of the prevalence of disability among population age groups, usually as self-reported in health surveys. The valuation of self-reported disability status is based on a simple dichotomous value of 0 (if people report being moderately or severely disabled, depending on the cut-off point) or 1 (if they report not being disabled). To calculate DFLE by SES, one of the data sources must also contain information on income, education or occupation.

66. DFLE has been adopted as a European Structural Indicator, and it is calculated and reported by Eurostat on a regular basis, using the EU-SILC as the source for the disability measure ${ }^{7}$. Work continues to develop the measure, with DG-SANCO and Eurostat establishing an EU Task Force on Health Expectancies in 2006. The strategic plan of the Task Force includes improving current Healthy Life Year (i.e. DFLE) estimates, improving international comparability, and calculating Healthy Life Years for SES groups (EU Task Force on Health Expectancies, 2007). This latter goal depends crucially, however, on achieving progress in calculating life expectancy by SES in a consistent way in EU countries.

67. A number of non-European countries have also calculated DFLE, using self-reported disability questions from their own national health or disability surveys. The US National Centre for Health Statistics currently uses three measures of Years of Healthy Life, including DFLE, to monitor the US 'Healthy People 2010' public health programme. Questions and response categories often differ across countries and surveys, and these will require standardisation if they are to be used for cross-national comparison. For instance, the question on disability used by the US National Center for Health Statistics (taken from the National Health Interview Survey) includes only two response categories (Yes, limited in activities or No, not limited), while the disability question in EU SILC includes three responses (Yes, severely limited; Yes, limited but not severely; No, not limited). There are also differences in the wording of the question. These differences can be expected to affect the comparability of overall prevalence rates of disability in the population, however, they probably have less impact if the focus is on examining the distribution of disability by SES within each country.

In March 2000, the Lisbon European Council invited the European Commission to present an annual report on progress achieved in the areas of employment, innovation, economic reform, social cohesion and the environment. 'Structural Indicators' allows quantitative evaluation and comparison of performances of the Member States in these areas. The DFLE Structural Indicator is also known as 'Healthy Life Years'. 


\section{DELSA/HEA/WD/HWP(2009)2}

68. The example in Figure 10 shows life expectancy for females with and without disability in England, as derived from the annual Health Survey for England. SES was measured by calculating material deprivation deciles, based on area of residence information from the 1991 Census. Females born during 1996-1999 could expect to live 60 years free of disability on average, but with wide variation, from 55 years in most deprived areas to 65 years in least deprived areas.

Figure 10: LE and DFLE at birth by deprivation deciles, females, England, 1996-1999

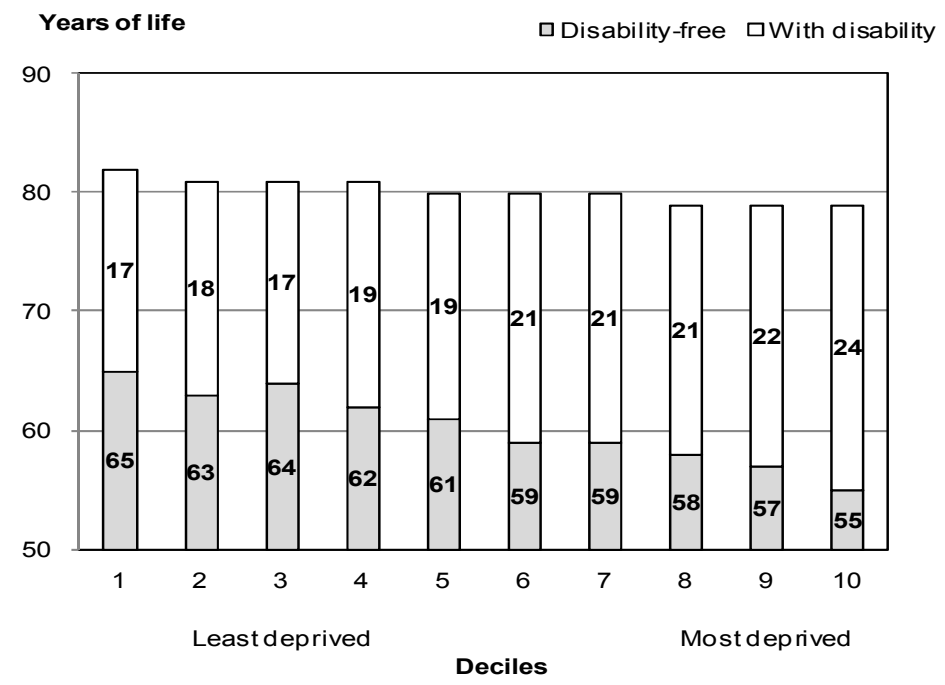

Source: Bajekal, 2005

\section{Health Adjusted Life Expectancy (HALE)}

69. Health Adjusted Life Expectancy (HALE) measures the number of years that an individual can expect to live in full health if current morbidity and mortality conditions prevail. It 'adjusts' life expectancy by weighing years of life lived in good health higher than years lived in poor health. The weighing of years of life depends on the valuation of different health conditions, with values ranging from 0 to 1 , where 0 represents death and 1 represents full health.

70. Information required to calculate HALE includes a life table in order to calculate life expectancies, a population health survey which describes the health status of the population, and a valuation of the different health conditions. HALE may be calculated for socioeconomic groups if both life expectancy and health status measures can be linked to the same SES measure. Valid cross-country comparisons are also subject to the same constraint.

71. HALE has been calculated for the 2001 Canadian population (Figure 11), using the Health Utility Index to describe and value health status. In this example, life expectancy at birth and at age 65 are presented for both males and females in different income groups. Both sexes in lower income groups can expect to live less years in full health. At birth, Canadian males in the lowest income group had a HALE almost five years lower than that for males in the highest income group; among females, HALE was three years lower (Health Canada, 2006). 
Figure 11: Health Adjusted Life Expectancy by sex and income level, at birth and age 65, Canada, 2001

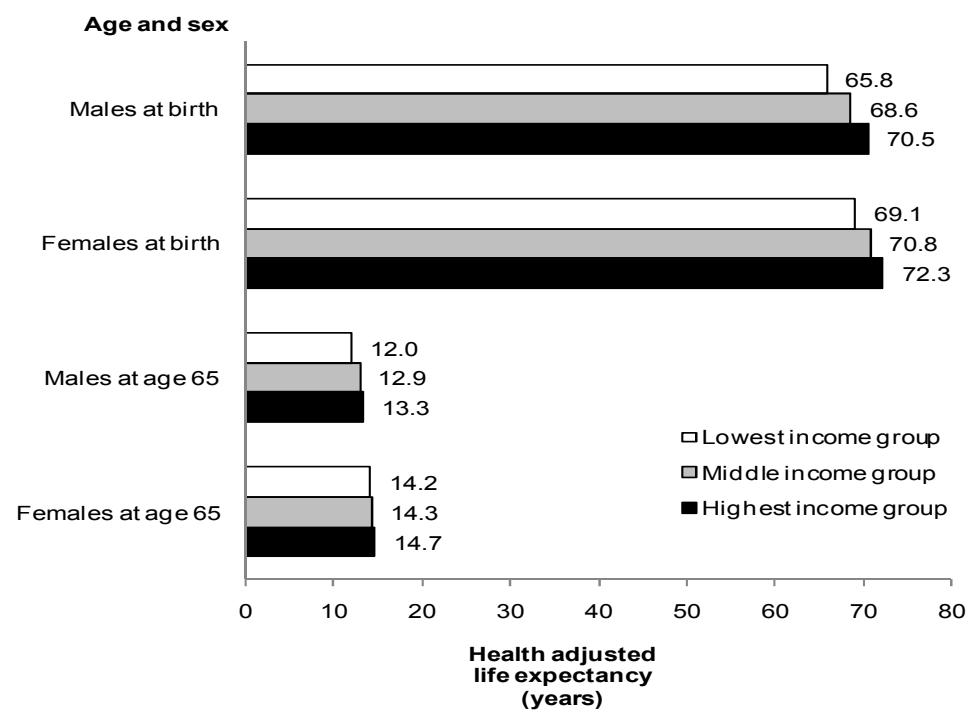

Source: Health Canada, 2006

\section{Disability Adjusted Life Years (DALY)}

72. A third summary health measure, the Disability Adjusted Life Year, or DALY, is also used to examine socioeconomic inequalities in health. The DALY is a 'health gap' measure that extends the concept of potential years of life lost due to premature death (YLL) to include equivalent years of 'healthy' life lost by virtue of being in states of poor health or disability (YLD). DALYs thus represent the sum of YLL and YLD, with one DALY representing the loss of one year of equivalent full health (Murray et al., 2002).

73. The calculation of DALYs requires a number of data sources. The YLL component is derived from information on numbers of deaths, and life expectancies at various ages, as sourced from life tables and mortality registers. The YLD component requires data on disease incidence and duration until remission or death, as well as a weight factor reflecting disease severity on a scale from 0 (perfect health) to 1 (death). It can be derived from various sources, including disease registers, hospital administrative data or health interview surveys.

74. DALYs have been used as summary measures of population health by the World Health Organization in their Global Burden of Disease Study and World Health Reports (Lopez et al., 2006), although data were not disaggregated by SES groups. Several countries have produced their own Burden of Disease reports, using DALYs to monitor health inequalities (e.g. Begg et al., 2007 for Australia).

75. DALYs have been calculated for the Australian population by SES, using 2003 mortality and morbidity/disability data. Not surprisingly, populations in areas with lower SES experienced proportionally higher burdens of disease in terms of disability and mortality than populations in areas with higher SES (Figure 12). The difference exceeded 30\% between the most and least disadvantaged populations (Begg et al., 2007). 


\section{DELSA/HEA/WD/HWP(2009)2}

Figure 12: DALY rates by socioeconomic quintile, age-standardised, Australia, 2003

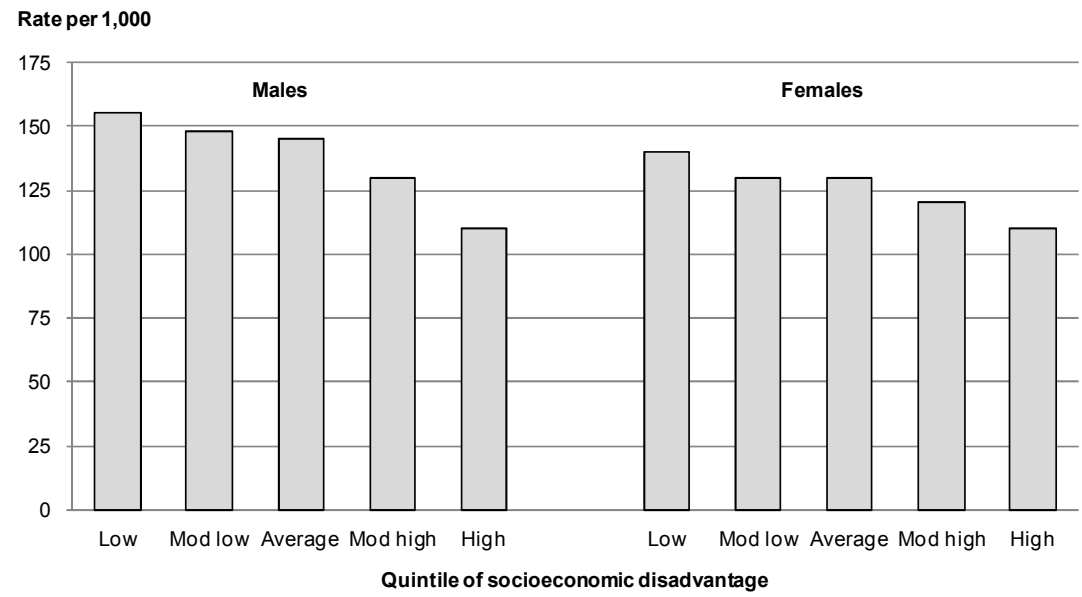

Source: Begg et al., 2007 


\section{INDICATORS OF INEQUALITIES IN HEALTH CARE ACCESS AND USE}

76. Ensuring adequate access to essential health services on the basis of individual need is a health policy goal in all OECD countries. Most countries further endorse the principle of 'equal access to equal care for equal need'. Almost all OECD countries have introduced universal health insurance coverage to ensure financial access to a core set of health services (OECD, 2007a). Despite this, inequalities in health care access and use remain for different reasons, and these may act to either mitigate or exacerbate inequalities in health status.

77. Health care access means people's ability to obtain appropriate health care services in a timely fashion and without obstacle. Some common barriers to access include financial reasons, a lack of health care providers, excessive travelling distance to providers, and excessive waiting time to see providers. Health care use relates to people's actual utilisation of different types of services (Academy Health, 2004). In determining inequities in health service utilisation, an adjustment to actual utilisation rates is often needed in order to compensate for people's differing needs for care, using available information such as their self assessed health status.

78. Measurement of inequalities in access and use may simply be in terms of comparing rates of unmet care or rates of service utilisation between low and high income groups. It may also be measured using more complex indices that seek to account for differences across the whole population, and not just between highest and lowest socioeconomic groups.

79. Indicators that are commonly used to gauge equity in health care access and use include the extent of public and private health insurance coverage across SES groups, the receipt or use of different types of health services (ideally adjusted for need, where applicable), the reporting of unmet care needs for various reasons, and the proportion of out-of-pocket expenditure in relation to household income or consumption. A discussion of each of these follows.

\subsection{Health insurance coverage}

80. One potential barrier to receiving appropriate health care is inadequate insurance coverage. Health insurance coverage provides financial security against the costs of unexpected illness and assists access to innovative treatments and preventative services. Most OECD countries have achieved universal coverage of health care costs for at least a core set of services, sometimes through combinations of public and private health insurance. Three countries that have not yet attained universal coverage are Mexico, Turkey and the United States (OECD, 2007a) (Figure 13). 
DELSA/HEA/WD/HWP(2009)2

Figure 13: Health insurance coverage for a core set of services, 2006 (or latest year available)

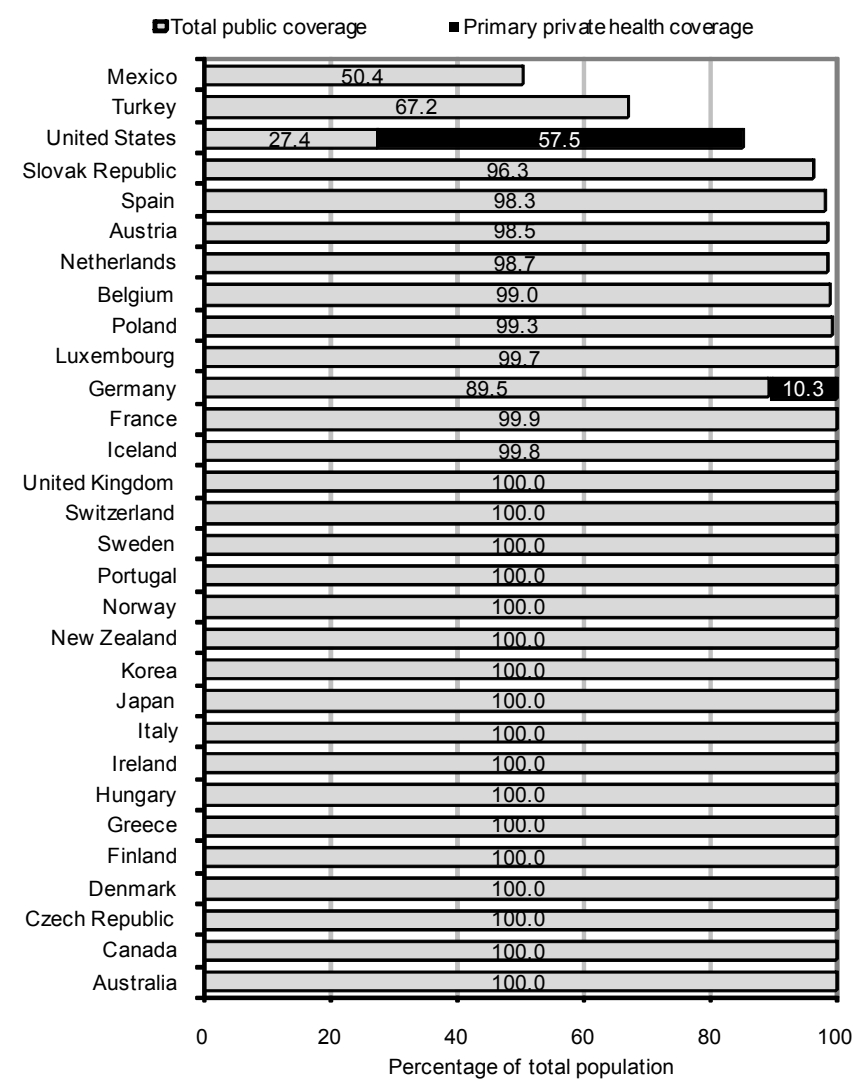

Source: OECD Health Data, 2008.

81. Data from the US National Health Interview Survey indicate that about $30 \%$ of persons aged less than 65 years who are deemed poor or near-poor do not have health insurance (Figure 14), compared to $10-15 \%$ of middle income and $5 \%$ of high income persons. The uninsured are more likely to have poorer health status and die early. They report more problems in getting care, are diagnosed at later disease stages and receive less therapeutic care. The uninsured are sicker when hospitalised and are more likely to die during their hospital stay. In the United States, the problem of persistent uninsurance is seen as a major barrier to receiving health care, and, more broadly, to reducing health inequalities (AHRQ, 2008). 
Figure 14: Persons aged less than 65 years with health insurance, by income, United States, 1999-2005

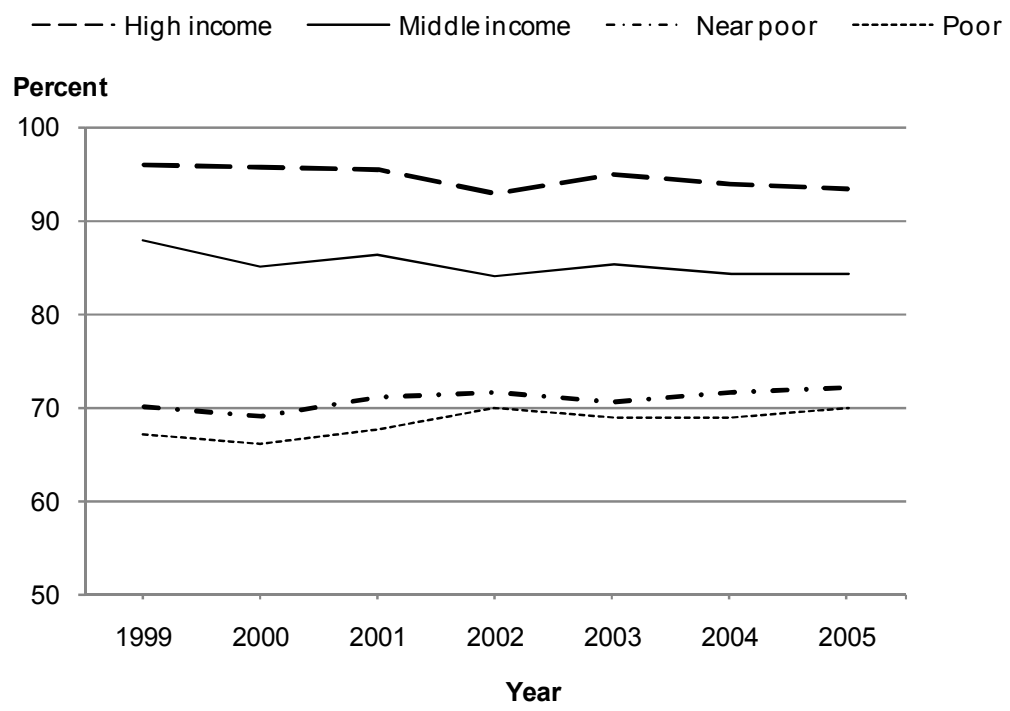

Source: AHRQ, 2008

82. Total population insurance coverage is imperfect in indicating health care accessibility, since the package of health goods and services included and the cost-sharing arrangements may vary from country to country, as well as within countries (OECD, 2007a). It is important to look at basic health insurance coverage in conjunction with other types of private health insurance coverage and out-of-pocket spending for health services (see next section on this latter topic).

83. Private health insurance plays a number of roles in OECD health systems, either as a primary or supplementary source of insurance coverage. Complementary or duplicate coverage is also possible (OECD, 2004c). In a number of countries, private health insurance coverage varies by SES. In Australia, $23 \%$ of persons in the lowest income quintile in 2004-05 had private health insurance, compared with $76 \%$ of those in the highest income quintile (ABS, 2006). In France, coverage of complementary health insurance is unequal across income groups, and poorer households spend proportionally more of their incomes to purchase it $(10.3 \%$ of income in the lowest income quintile vs. $2.9 \%$ in the highest) (KambiaChopin et al., 2008). Private health insurance need not necessarily create access inequities, however, especially if voluntary schemes complement what are otherwise fairly equitable distributions of care (OECD, 2004b).

84. OECD Health Data already collects data on public and private health insurance coverage, although not disaggregated by income group. In countries that do not have universal health insurance coverage, data on public and/or private health insurance coverage by SES may be collected through health interview or household surveys.

\subsection{Out-of-pocket expenditure}

85. Measuring the financial burden of out-of-pocket spending on households is important, since these burdens can create barriers to health care access and/or use. Households having difficulties paying medical bills may delay or forgo needed health care (Hoffman et al., 2005; May \& Cunningham, 2004, cited in Banthin et al., 2008). 


\section{DELSA/HEA/WD/HWP(2009)2}

86. In contrast to publicly-funded care, out-of-pocket payments are distributed based on the use of care, and not on the ability to pay. If the financing of health care becomes more dependent on out-ofpocket payments, its burden is, in theory, shifted towards those who use the services more (possibly from rich to poor, if health care needs are higher for the low income groups). In practice, many countries have put in place exemptions and caps to out-of-pocket payments for lower income groups to protect health care access.

87. The burden of out-of-pocket health spending on households can be measured either by its share of total household income or its share of total household consumption. Data presently collected under OECD Health Data show that the average share of out-of-pocket spending in household consumption varies considerably across OECD countries in 2006, representing less than $2 \%$ of total household consumption in countries such as the Netherlands and France, while such spending accounted for more than $6 \%$ of total household consumption in Switzerland and Greece. The United States, with almost 3\% of consumption being spent on out-of-pocket health services, is close to the average.

88. The distribution of spending across the population can vary considerably, depending on whether such spending is affected by income, service use, type of coverage, or other factors. For instance, an analysis of data from the US Medical Expenditure Survey found that $28 \%$ of Americans living in a poor family (defined as a family income below the federal poverty level) were spending more than $10 \%$ of their after-tax family income for health services and health insurance premiums in 2004 , compared with $10 \%$ of Americans living in a high income family (Banthin et al., 2008). ${ }^{8}$

89. A 2007 Commonwealth Fund survey found that - in addition to almost 50 million people who were uninsured in the US - an estimated 25 million people aged 19-64 (or 14\% of all adults) were underinsured, a $60 \%$ increase since 2003. Persons were defined as 'underinsured' if they experienced at least one of the three indicators of financial expenditure exposure relative to income: (1) out-of-pocket medical expenses for care amounted to $10 \%$ of income or more, (ii) among low-income adults (below $200 \%$ of the federal poverty level), medical expenses amounted to at least $5 \%$ of income, or (iii) deductibles equalled or exceeded $5 \%$ of income. Underinsurance varied by SES group, from $7 \%$ of adults earning USD 100000 or more, to $26 \%$ of adults earning less than USD 20000 per annum. In total, $42 \%$ of US adults were found to be underinsured or uninsured, reporting high levels of access problems and financial stress (Schoen et al., 2008).

90. A small proportion of households in OECD countries face "catastrophic" health expenditure each year, often defined as payments for health services exceeding $40 \%$ of their disposable income after subsistence needs are met. In Portugal, Spain, Switzerland and the United States, rates of catastrophic spending exceed $0.5 \%$ (Xu et al., 2007). The incidence of financial catastrophe in the lowest income quintile would be expected to exceed that in higher quintiles; however the imposition of user fees may mean that households in lower income quintiles do not use enough services to incur catastrophic expenditures.

91. Information on the share of out-of-pocket expenditure in total household income or consumption disaggregated by income group is collected through regular household expenditure surveys in a number of

$8 \quad$ Another analysis of data from the US Consumer Expenditure Survey found that Americans under the age of 35 spent an average of $2.7 \%$ of their income on health care, as compared with $12.9 \%$ among those 65 and over, despite the fact that insurance coverage through Medicare is universal for the latter group, while about $15 \%$ of those 35 and under lack health insurance coverage. Those with incomes under USD 20000 spent $15.2 \%$ of their income on health care, compared with $2.6 \%$ of those with incomes of USD 70000 and above. This analysis is presented in a Medicare chart book available on the website of the US Centres for Medicare and Medicaid Services (www.cms.gov). 
OECD countries. Some further developmental work would be needed to obtain comparable data on this type of measure across countries.

\subsection{Health care utilisation}

92. Socioeconomic status is an important factor in determining how populations utilise health care services. Income, education and occupational status affect health care need, recognition and response to health symptoms, knowledge of disease, and access and choice of health services. Although people in lower socioeconomic groups tend to have higher rates of disease and mortality, they do not necessarily utilise health care at greater rates.

93. After adjusting for differences in the need for health care, the use of primary health care is generally found to be equitable or fairly distributed, but research has found a 'pro-rich' bias in the use of specialist and dental care, as well as in the use of preventative services such as breast and cervical cancer screening (Van Doorslaer \& Masseria in OECD, 2004b; Mielck et al. in Mackenbach \& EUROTHINE, 2007; WHO, 2008; Gakidou, 2008).

94. Van Doorslaer \& Masseria (OECD, 2004b) used a sophisticated measure, the concentration index, to measure income-related inequality in the use of various types of medical care in OECD countries. The study aimed at comparing the actual distribution of medical and dental care by income, adjusted by need. Survey data were sourced from the European Community Household Panel conducted in 2000 by Eurostat, as well as from national health surveys in non-EU countries. Results for specialist visits are shown in Figure 15. Even after health service need was accounted for, higher income persons in all surveyed countries - except the United Kingdom, the Netherlands and Norway - were more intensive users of specialist visits than lower income groups. This was especially so for Portugal, Finland, Ireland and Italy, four countries where private insurance and direct private payments play a role in accessing specialist services. More recent research has also found that, after controlling for need, people with higher education levels in nine European countries tend to use specialist care more than less-educated people (Or et al., 2008).

Figure 15: Horizontal inequity indices for specialist care use in 17 countries, 2000 or nearest available year

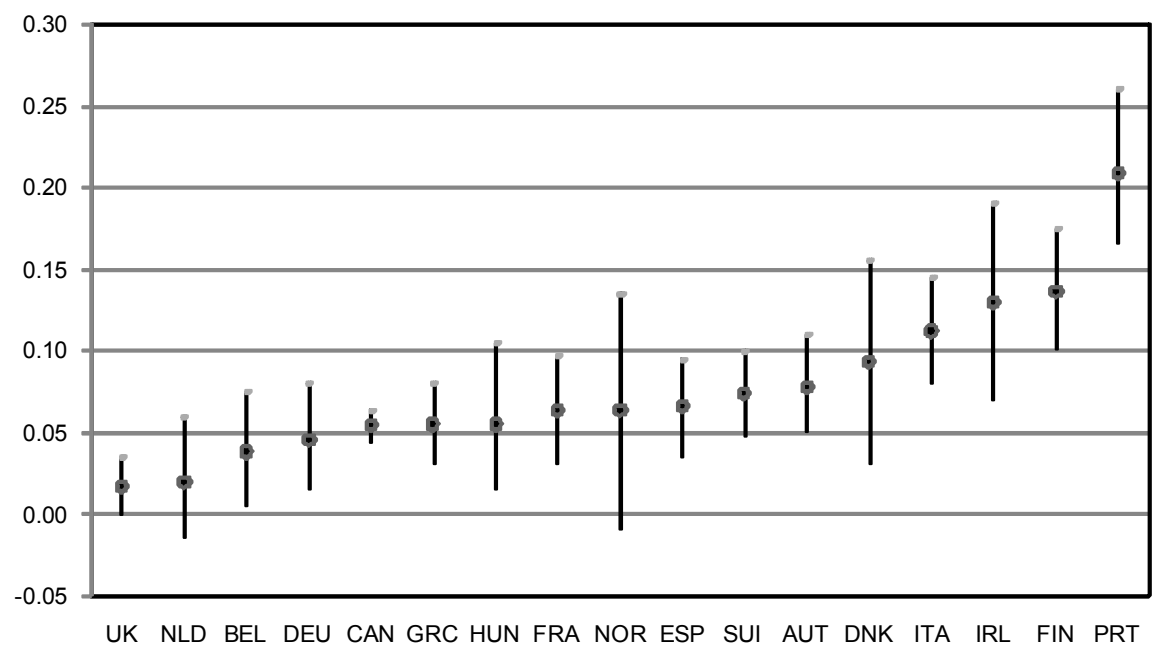

Note: Specialist care is inequitable (in this case, favouring high income groups) if the $95 \%$ confidence limit is significantly different from zero. This is so for all countries, except the United Kingdom, the Netherlands and Norway.

Source: van Doorslaer \& Masseria et al., in OECD, 2004b 


\section{DELSA/HEA/WD/HWP(2009)2}

95. Table 4 presents data from the Dutch National Survey of General Practice, carried out in 2001. After correcting for demographics and for self-rated health, less educated persons visited GPs more often than persons with higher education levels, but their utilisation rates were significantly lower for a number of services, including dental visits, psychosocial care and Pap smear use (cervical cancer screening). Further exploration of these data found lower utilisation of care among certain immigrant populations and asylum seekers, among persons in disadvantaged neighbourhoods and among marginalised groups such as illegal residents (Westert \& Verkleij, 2006).

96. Health interview surveys are a major source of data on both health care use and socioeconomic status. By also using available information on age, sex and health status, it is possible to adjust health care use by some measure of need where applicable, as illustrated by the results from the Dutch survey. However, the reliability of survey estimates depend on the methodology used and an adequate sample size, while the comparability of data across countries depends on the harmonisation of questions and other aspects of survey methodologies. There is also some doubt as to whether the reception of evidence-based necessary care can be accurately assessed through self-report questionnaires.

Table 4: Care utilisation by level of education, persons aged over 25, The Netherlands, 2001

\begin{tabular}{|c|c|c|c|c|c|}
\hline & \multicolumn{3}{|c|}{ Level of education (per cent) } & \multicolumn{2}{|c|}{ Odds ratio } \\
\hline & Low & Middle & High & $\begin{array}{l}\text { Corrected for } \\
\text { demographics }\end{array}$ & $\begin{array}{c}\text { Corrected for } \\
\text { demographics and } \\
\text { self-rated health }\end{array}$ \\
\hline General practitioner & 51 & 42 & 36 & $1.4^{*}$ & 1.2 \\
\hline Physiotherapist & 16 & 16 & 14 & 1.3 & 1.1 \\
\hline Home care & 14 & 6 & 3 & 1.3 & 1.1 \\
\hline Dentist & 39 & 76 & 86 & $0.2^{*}$ & $0.2 *$ \\
\hline Medical specialist & 26 & 21 & 19 & 1.1 & 0.9 \\
\hline $\begin{array}{l}\text { Admission to hospital, nursing } \\
\text { home or rehabilitation centre }\end{array}$ & 11 & 7 & 6 & 1.2 & 1.0 \\
\hline Psychosocial care & 15 & 20 & 30 & $0.5^{*}$ & $0.5^{*}$ \\
\hline Alternative medicine & 5 & 7 & 9 & 0.7 & 0.6 \\
\hline Prescribed medicines & 23 & 16 & 13 & 1.3 & 1.0 \\
\hline Pap smear (women aged 30-59) & 75 & 82 & 85 & $0.5^{*}$ & $0.6^{*}$ \\
\hline $\begin{array}{l}\text { X-rays breast (women aged } 18 \\
\text { and over) }\end{array}$ & 46 & 38 & 29 & 0.8 & 0.8 \\
\hline \multicolumn{6}{|c|}{$\begin{array}{l}\text { Notes: } \\
\text { (1) Odds ratio }>1 \text { indicates people with low level of education use more care than people with high level of education. Similarly, }<1 \\
\text { indicates the use of less care. } \\
\text { (2) * indicates statistically significant } \mathrm{p}<0.05 \text {. } \\
\text { (3) Care utilisation in past year, except general practitioner and medical specialist (past } 2 \text { months), psychosocial care (ever), prescribed } \\
\text { medicines (past } 2 \text { weeks), Pap smear (past } 5 \text { years) and X-rays breast (past } 2 \text { years). }\end{array}$} \\
\hline
\end{tabular}

Source: Westert \& Verkleij, 2006

97. In reviewing different methods used to measure inequalities in health care utilisation, Wagstaff et al. (1991) noted that there were two - the slope index of inequality and the concentration index - that were able to present a complete picture of socioeconomic inequalities in health. These two indices use all 
available data, and do not focus simply on those persons in the highest and lowest SES groups. Of the two, the concentration index provides a means of quantifying the degree of socioeconomic-related inequality in a specific health variable (O'Donnell et al., 2008). The concentration index measure has been criticised by some researchers on the grounds that it is difficult to calculate and interpret, and it is open to misunderstanding (Mackenbach \& Kunst, 1997). One option for policy makers and researchers is to use the concentration index as an adjunct to more simple and straightforward measures of health inequality.

\subsection{Unmet care needs}

98. An additional measure of health care access is whether people report an unmet care need for some reason, whether a doctor visit, a dental consultation, a hospital admission or another type of care. In order to determine unmet care, individuals are typically asked health interview questions of the nature: "Was there a time in the previous 12 months that you felt you needed health care services but did not receive them?", followed by a question to determine why the need for care was unmet. Such questions are a feature of a number of national and cross-national health interview surveys, including EU-SILC, the recommended health care module in EHIS, the Survey of Health, Ageing and Retirement in Europe (SHARE), the international health policy surveys conducted by the Commonwealth Fund, and the Joint Canada/United States Survey of Health.

99. Research indicates that unmet care needs are experienced mostly by people with low SES, whether through low income, lack of insurance coverage, or because they come from a racial or ethnic minority group. Common reasons given for care needs not being met include excessive costs of care, excessive waiting times to receive care, or having to travel too far to receive care (Sanmartin et al., 2004; Mielck et al., in Mackenbach \& EUROTHINE, 2007).

100. The International Health Policy surveys regularly conducted by the Commonwealth Fund report on unmet care among a number of non-European countries, as well as in Germany, the Netherlands and the United Kingdom (Figure 16). The 2007 survey found that foregone care for a number of different treatments due to costs remains more prevalent among lower income groups, although the level is much lower in the United Kingdom than in the United States. In the United States, adults with below-average incomes who have health insurance report significantly fewer access problems due to cost than their uninsured counterparts (Blendon et al., 2002). 
Figure 16: Persons reporting an unmet care need ${ }^{(a)}$ due to costs in 7 countries, by income group, 2007

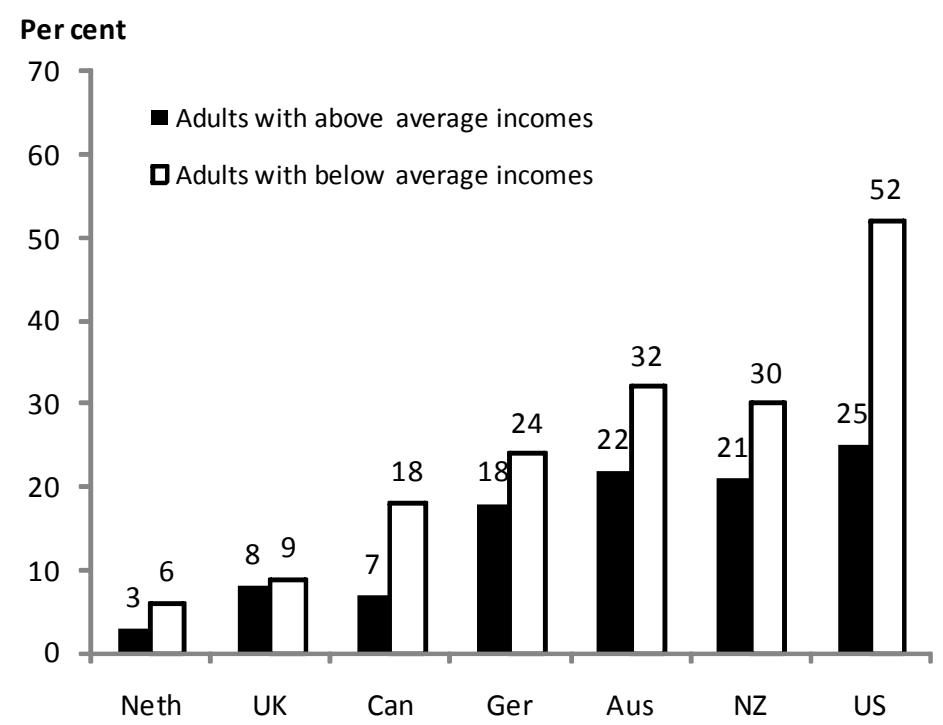

(a) "Needed care" in this instance can mean any of the following: unfilled prescriptions or missed medication; had a medical problem but did not visit doctor; or missed tests, treatment or follow-up.

Source: Commonwealth Fund, 2008

101. The EU-SILC collects data on unmet medical and dental care needs in a majority of OECD countries. In Europe, higher rates of unmet need for medical examinations among the adult population were reported in Poland (9.3\%), Greece (5.8\%) and Portugal (5.0\%) in 2006 (Figure 17). But inequalities within countries were greater in countries such as Belgium, Portugal and the Slovak Republic, although in Belgium the overall reported level of unmet care is low (less than 1\%). 
Figure 17: Persons reporting an unmet need for a medical examination because of problems of access, by income quintile, 2006

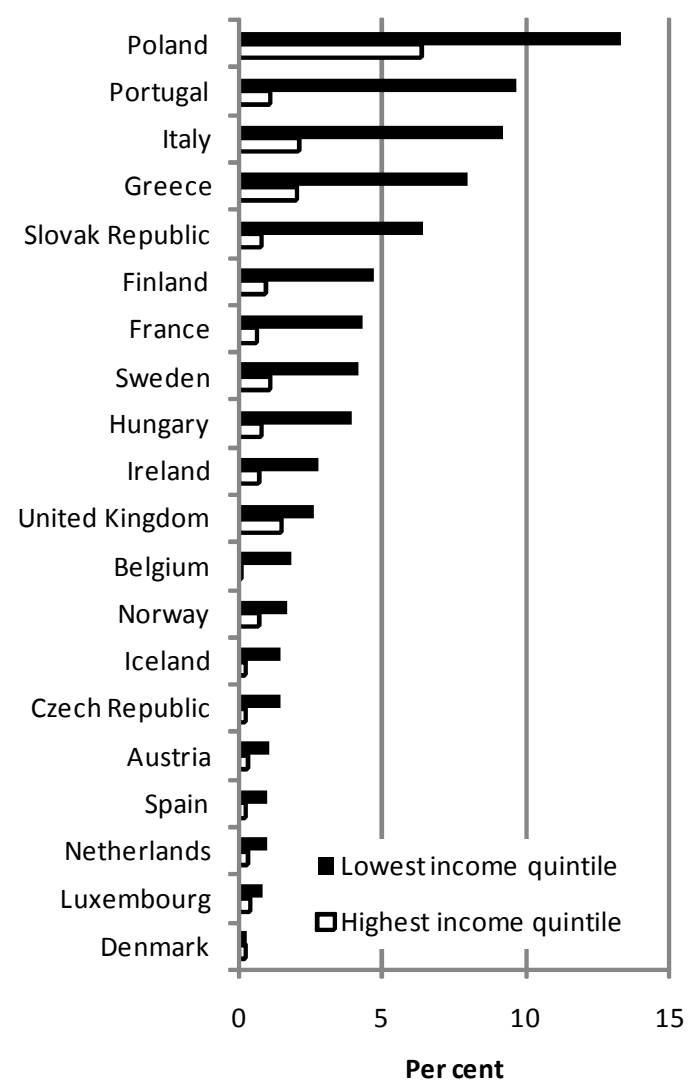

Note: Data for Germany are not reported due to methodological issues.

Source: EU-SILC

102. In 2006, participating European countries also reported differing rates of unmet need for dental care among the total adult population (Table 5), but all countries reported higher rates among lower SES groups. Large disparities exist between quintile 1 (lowest income) and quintile 5 (highest income) in Belgium, Denmark, Luxembourg, Portugal and Sweden. Note, however, that in Belgium and Luxembourg, the proportion of the population reporting unmet dental care need in each quintile is relatively small.

103. Information both on unmet care need and socioeconomic status can be derived from the same collection instrument, and data are available for a large number of countries, albeit the specific questions and answers vary across surveys/countries (see Annex 2). Since a number of these surveys are ongoing, annual data has the potential to provide a picture of trends in socioeconomic inequalities in unmet care needs. Various cross-national studies have used this indicator to examine access to care among socioeconomic groups (Schoen et al., 2007; Sanmartin et al., 2004; Mackenbach \& EUROTHINE, 2007; Huber et al., 2008). 
DELSA/HEA/WD/HWP(2009)2

Table 5: Proportion of adults reporting unmet needs for dental examination, by income quintile, selected EU countries, 2006

\begin{tabular}{lcccccc}
\hline & $\begin{array}{c}\text { Quintile 1 } \\
\text { (Lowest } \\
\text { income) }\end{array}$ & Quintile 2 & Quintile 3 & Quintile 4 & $\begin{array}{c}\text { Quintile 5 } \\
\text { (Highest } \\
\text { income) }\end{array}$ & Total \\
\hline Austria & 1.6 & 1.2 & 0.7 & 0.5 & 0.7 & $\mathbf{0 . 9}$ \\
Belgium & 3.8 & 1.7 & 0.7 & 0.4 & 0.1 & $\mathbf{1 . 3}$ \\
Czech Republic & 1.8 & 1.0 & 0.8 & 0.6 & 0.3 & $\mathbf{0 . 9}$ \\
Denmark & 6.7 & 2.5 & 1.4 & 0.9 & 0.5 & $\mathbf{2 . 4}$ \\
Finland & 7.7 & 5.8 & 4.7 & 3.7 & 3.5 & $\mathbf{5 . 1}$ \\
France & 6.6 & 4.3 & 3.4 & 1.7 & 0.9 & $\mathbf{3 . 4}$ \\
Greece & 8.7 & 6.8 & 7.2 & 3.7 & 1.8 & $\mathbf{5 . 6}$ \\
Hungary & 7.7 & 6.8 & 4.3 & 2.8 & 2.8 & $\mathbf{4 . 9}$ \\
Iceland & 10.1 & 9.5 & 7.8 & 4.3 & 1.5 & $\mathbf{6 . 7}$ \\
Ireland & 3.2 & 2.7 & 2.5 & 1.7 & 1.1 & $\mathbf{2 . 2}$ \\
Italy & 12.4 & 8.5 & 6.5 & 4.6 & 2.6 & $\mathbf{6 . 9}$ \\
Luxembourg & 2.7 & 0.8 & 0.2 & 0.2 & 0.1 & $\mathbf{0 . 8}$ \\
Netherlands & 2.4 & 1.6 & 0.9 & 0.3 & 0.4 & $\mathbf{1 . 1}$ \\
Norway & 13.1 & 8.2 & 5.3 & 4.4 & 1.8 & $\mathbf{6 . 5}$ \\
Poland & 14.7 & 10.9 & 9.0 & 7.5 & 5.6 & $\mathbf{9 . 5}$ \\
Portugal & 16.4 & 12.2 & 9.9 & 6.6 & 1.6 & $\mathbf{9 . 3}$ \\
Slovak Republic & 6.5 & 3.8 & 3.8 & 2.2 & 1.2 & $\mathbf{3 . 5}$ \\
Spain & 5.7 & 5.0 & 4.0 & 2.0 & 0.9 & $\mathbf{3 . 5}$ \\
Sweden & 15.3 & 10.3 & 6.6 & 5.3 & 1.5 & $\mathbf{7 . 7}$ \\
United Kingdom & 6.1 & 3.8 & 4.4 & 4.2 & 3.7 & $\mathbf{4 . 4}$ \\
20 OECD countries & $\mathbf{7 . 7}$ & $\mathbf{5 . 4}$ & $\mathbf{4 . 2}$ & $\mathbf{2 . 9}$ & $\mathbf{1 . 6}$ & $\mathbf{4 . 3}$ \\
\hline
\end{tabular}

Note: Data for Germany are not reported due to methodological issues.

Source: EU-SILC 


\section{CONCLUSION}

104. This paper has surveyed indicators that might be used to measure socioeconomic inequalities in health status, and in health care access and use.

105. Based on the criteria of policy relevancy, interpretability and data availability across countries, a number of potential indicators are suggested, along with an indication of how frequently these indicators might be collected. To allow broad comparisons across OECD countries, improvements in data availability and comparability would need to be made for many of the suggested indicators. Regarding mortality-based measures, the main challenge for countries is to link data from mortality registers to a measure of socioeconomic status (SES). For the purpose of international comparison, the same measure of SES (be it income, education or occupation) would need to be used in all countries. Regarding morbidity-based measures, the main challenge is to further harmonise a key set of questions in national health survey modules on health status and health care use, and to be able to link this information with a standard measure of SES. This is currently being done in Europe through the development of the European Health Interview Survey. Comparisons might also be broadened by expanding the country coverage in multicountry surveys, such as those conducted by the Commonwealth Fund.

106. Survey-based measures of health status and of health care access and use might be subject to a number of potential limitations, such as cultural biases, recall biases, different coverage of the population (e.g., inclusion or exclusion of the population in institutions), and issues related to the representativeness of the survey sample. Nonetheless, health-related surveys remain a unique source of data in most countries to measure socioeconomic inequalities in health status and health care access and use. While cultural factors might affect responses to survey questions that are more subjective in terms of the average level across countries, they are likely to have a lesser impact if the focus of the analysis is on disparities across socioeconomic groups within each country (assuming that the different socioeconomic groups in each country share common cultural characteristics).

107. The indicators of socioeconomic inequalities in health and health care access judged at this stage to be feasible for regular (i.e. annual or biennial) collection include: self-rated health, self-rated disability, and measures of unmet care needs. Indicators that are judged feasible to collect for a reasonable number of countries, but which are more suited to periodic collection (i.e. every three to five years) include: life expectancy, total mortality rate, infant mortality rate, the proportion of the population who do not have any health care coverage (for the few countries where this may be relevant), measures of health care use (adjusted where appropriate for need), and the share of out-of-pocket expenditure. Collection of the different indicators of healthy life expectancy (disability-free life expectancy, health adjusted life expectancy, and disability adjusted life years) is less feasible, given the current state of data development.

108. The examples discussed in this paper help underline some of the issues involved in making valid multi-country comparisons of health inequality, not the least of which are harmonisation of definitions and measurement instruments, and the need for data linkages in order to allow disaggregation by SES. The effort made to improve data availability and comparability will determine whether health inequalities can be regularly monitored across most or all OECD Countries. 


\section{GLOSSARY OF TERMS}

Health care access - An individual's ability to obtain appropriate health care services. (Academy Health, 2004)

Health care financing - The different methods of paying for health care.

Health care use (or utilisation) - Commonly examined in terms of patterns or rates of use of a single service or type of service (e.g. hospital care, physician visits, prescription drugs). Use is also expressed in rates per unit of population at risk for a given period. (Academy Health, 2004)

\section{Health disparities (or differences) - See health inequalities}

Health inequalities - Variations in health status, health care access and use, and other health indicators, between individuals and groups. With respect to health status, health inequalities have been defined as differences in the prevalence or incidence of health problems between individuals or groups. (Kunst \& Mackenbach, 1995)

Health inequities - Health inequalities that are deemed to be unfair, or which stem from some form of social injustice (Kawachi et al., 2002). Equity in health care access means that people's needs should guide the distribution of opportunities for well-being.

Health status - An individual's or populations' overall level of health, taking account of various aspects such as life expectancy, amount of disability, levels of disease risk factors and so forth. Conceptually, health status is the proper outcome measure for the effectiveness of a specific population's medical care system, although attempts to relate effects of available medical care to variations in health status have proved difficult. (Academy Health, 2004)

Progressivity - The extent to which the burden of health finance increases as individual or household income increases.

Socioeconomic status (SES) - An individual's or family's relative position in society, usually expressed in terms of income, education or occupation.

Summary measures of population health - Measures that combine information on mortality and non-fatal health outcomes to represent population health in a single number (WHO, 2003). 


\section{ANNEX 1: A SUMMARY OF THE "EFFECTIVE COVERAGE" MEASURE}

109. The notion of "effective coverage" was introduced several years ago as a way of refining the WHO framework for health system performance assessment (WHO, 2003). It has been defined as "the proportion of potential health gain that can be delivered through an intervention by the health system that is actually delivered" (Lozano et al., 2006). If, for example, a health system could increase life expectancy for women by two years through early detection and treatment for cervical cancer, but delivers only one year, then effective coverage for this health problem is $50 \%$. Effective coverage attempts to bring together measures of the use of interventions, conditional on need, with the quality of the intervention delivered.

110. One of the first countries which tried to implement a measure of effective coverage was Mexico, and some initial results are presented in Figure 18. Using data collection systems including health examination surveys, vital registrations and hospital discharge information, 14 different health interventions were monitored in 2005-06. ${ }^{9}$ Effective coverage for these 14 interventions taken together was found to vary across different areas of Mexico, from $54 \%$ in Chiapas, a poor state, to $65 \%$ in the more affluent Federal District. Effective coverage for maternal and child health interventions varied by household wealth, from $52 \%$ for the lowest wealth quintile to $61 \%$ for the highest quintile. Inequalities existed between income quintiles for the combination of all 14 interventions measured, for maternal and child health coverage ( 8 interventions) and for other adult interventions ( 6 interventions). The absolute gap in effective maternal and child health coverage was $9 \%$ between lowest and higher income quintiles, and $14 \%$ for other adult interventions (Lozano et al., 2006).

111. The selection of interventions to monitor is dependent on available data, and several sources may be needed. These include biomedical data (e.g. to test for HIV infection, blood pressure, blood sugar or cholesterol). A number of important questions need to be answered in order to determine effective coverage, namely, who needs an intervention, who receives the intervention and what was the quality of the intervention? Answering each of these requires measurement. To enable cross-country comparison, a core set of coverage indicators and a standard survey module are needed, with measurement of the distribution of coverage carried out across all socioeconomic groups. Effective coverage may have broad applicability in both developing and developed countries, although substantial data developmental work would be needed to implement this approach at the national and international level.

The interventions are: measles immunisation, DTP3 immunisation, antenatal care, skilled birth attendance, services delivered to premature babies, treatment of acute respiratory infections in children, treatment of diarrhoea in children, breast cancer screening, cervical cancer screening, treatment of vision disorders, treatment of hypertension, treatment of hypercholesterolaemia, influenza vaccine. 


\section{DELSA/HEA/WD/HWP(2009)2}

Figure 18: Effective coverage for health interventions, by household wealth quintile, Mexico, 2005-06

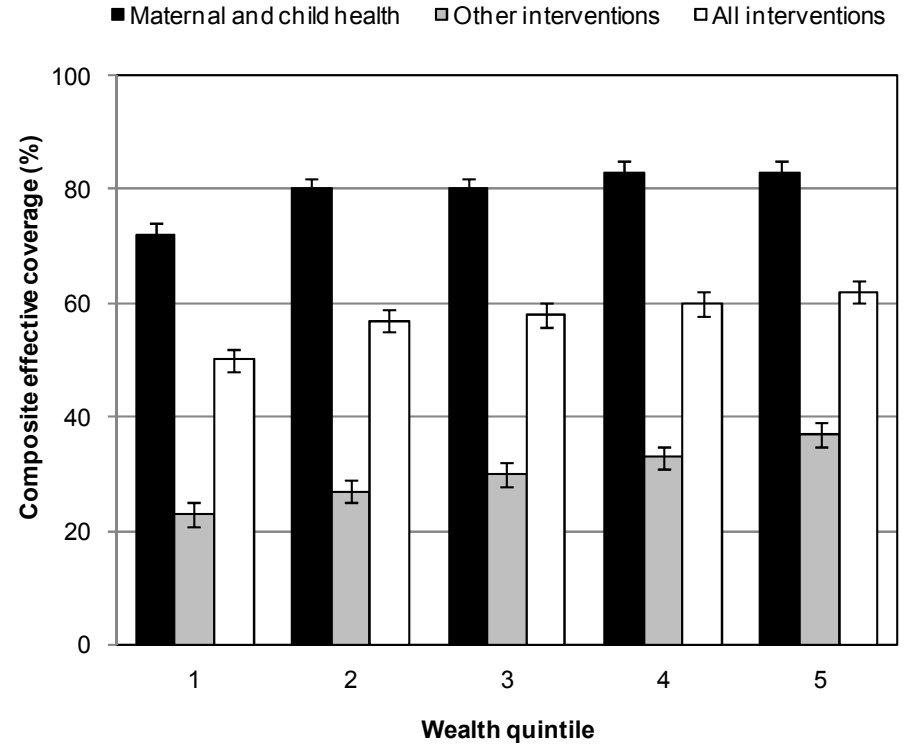

Source: Lozano et al., 2006 


\section{ANNEX 2: QUESTIONS ON SELF-RATED HEALTH AND DISABILITY AND HEALTH CARE ACCESS IN CROSS-NATIONAL SURVEYS}

\section{Self-rated health}

European Union Statistics on Income and Living Conditions (EU-SILC)

How is your health in general? Is it:

Very $\mathrm{good} /$ Good/Fair/Bad/Very bad

European Health Interview Survey (EHIS)

How is your health in general? Is it:

Very $\mathrm{good} /$ Good/Fair/Bad/Very bad

Survey of Health, Ageing and Retirement in Europe (SHARE)

Would you say your health is:

Excellent/Very good/Good/Fair/Poor

\section{Commonwealth Fund International Health Policy Survey}

In general, how would you describe your own health?

Excellent/Very good/Good/Fair/Poor

\section{Joint Canada/United States Survey of Health}

In general, would you say your health is:

Excellent/Very good/Good/Fair/Poor

\section{Self-rated disability}

European Union Statistics on Income and Living Conditions (EU-SILC)

For at least the last 6 months have you been limited in activities people usually do, because of a health problem?

Yes, strongly limited/Yes, limited/Not limited 
DELSA/HEA/WD/HWP(2009)2

\section{European Health Interview Survey (EHIS)}

For at least the past 6 months, to what extent have you been limited because of a health problem in activities people usually do?

Severely limited/Limited but not severely/Not limited at all

(The survey includes other questions on seeing, hearing, walking, climbing stairs, bending, carrying, gripping, biting \& chewing)

\section{Survey of Health, Ageing and Retirement in Europe (SHARE)}

Some people suffer from chronic or long-term health problems. By long-term we mean it has troubled you over a period of time or is likely to affect you over a period of time. Do you have any long-term health problems, illness, disability or infirmity?

Yes/No

For the past six months at least, to what extent have you been limited because of a health problem in activities people usually do?

Severely limited/Limited, but not severely/Not limited

(The survey includes other questions on seeing, hearing, walking, climbing stairs, bending, carrying, gripping, biting \& chewing)

\section{Commonwealth Fund International Health Policy Survey}

Have you had a serious or chronic illness, injury, or disability that has required a lot of medical care in the past 2 years?

$\mathrm{Yes} / \mathrm{No}$

\section{Joint Canada/United States Survey of Health, 2002-03}

The next few questions deal with any limitations in your daily activities caused by a health condition or problem. In these questions, "long-term conditions" refer to conditions that have lasted or are expected to last 6 months or more.

Do you have any difficulty hearing, seeing, communicating, walking, climbing stairs, bending, learning or doing any similar activities?

\section{Sometimes/Often/Never}

How often does a long-term physical condition or mental condition or health problem, reduce the amount or the kind of activity you can do:

Sometimes/Often/Never 


\section{Unmet care needs}

\section{European Union Statistics on Income and Living Conditions (EU-SILC)}

Was there any time during the last 12 months when you personally, really needed a $<$ dental examination or treatment $><$ medical examination or treatment for a health problem $>$ but you did not receive it?

\section{Yes/No}

What was the main reason for not consulting a $<$ dentist $><$ medical specialist $>$ ?

Could not afford to (too expensive)/Waiting list/Could not take time off work (or could not take time off from caring for children or others)/Too far to travel or no means of transport/Fear of $<$ dentist $>$, $<$ doctor $>$, examination, treatment/Wanted to wait and see if problem got better on its own/Didn't know any good $<$ dentist $><$ doctor or specialist $>/$ Other reason

\section{European Health Interview Survey (EHIS)}

During the past 12 months, was there any time when you really needed to $<$ be hospitalised, following a recommendation from a doctor, either as an inpatient or a day patient $><$ consult a specialist $>$ but did not?

Yes, there was at least one occasion/No, there was no occasion

What was the main reason for not $<$ being hospitalised $><$ consulting a specialist $>$ ?

Could not afford to (too expensive or not covered by the insurance fund)/Waiting list <other reasons due to the hospital> <don't have the referral letter $>$ /Could not take time because of work, care for children or for others/Too far to travel, no means of transportation/Fear of $<$ surgery, treatment $><$ doctor, hospitals, examination, treatment $>/<$ Didn't know any good specialist $>/$ Other reason

\section{Survey of Health, Ageing and Retirement in Europe (SHARE)}

During the last twelve months, did you forgo any types of care because $<$ of the costs you would have to pay $><$ they were not available or not easily accessible $>$

\section{Yes/No}

Which types of care did you forgo because $<$ of the costs you would have to pay $><$ they were not available or not easily accessible>

Surgery/Care from a general practitioner/Care from a specialist physician/Drugs/Dental care/Hospital (inpatient) rehabilitation/Ambulatory (outpatient) rehabilitation/Aids and appliances/Care in a nursing home/Home care/Paid home help/Any other care not mentioned on this list 


\section{Commonwealth Fund International Health Policy Survey}

During the past 12 months, was there a time when you $<$ Had a medical problem but did not visit a doctor because of cost $><$ Skipped a medical test, treatment, or follow-up that was recommended by a doctor because of the cost $><$ Did not fill/collect a prescription for medicine, or you skipped doses of your medicine because of the cost $><$ Needed dental care but did not see a dentist because of the cost $>$

Yes/No/Not applicable

\section{Joint Canada/United States Survey of Health}

During the past 12 months, was there ever a time when you felt that you needed health care but you didn't receive it?

Yes/No

Thinking of the most recent time, why didn't you get care?

Not available in the area/Not available at time required (e.g. doctor on holidays, inconvenient hours)/Waiting time too long/Felt would be inadequate/Cost/Too busy/Didn't get around to it, Didn't bother/Didn't know where to go/Transportation problems/Language problems/Personal or family responsibilities/Dislikes doctors, Afraid/Decided not to seek care/Other

Again, thinking of the most recent time, what was the type of care that was needed?

Treatment of a physical health problem/Treatment of an emotional or mental health problem/A regular check-up (including regular pre-natal care)/Care of an injury/Other 


\section{BIBLIOGRAPHY}

ABS (Australian Bureau of Statistics) (2004), Disability, Ageing and Carers: Summary of Findings, Australia, 2003, Cat. No. 4430.0, ABS, Canberra.

ABS (2006), Private Health Insurance: a Snapshot, 2004-05, Cat. No. 4815.0.55.001, ABS, Canberra.

ABS (2007), Self-Assessed Health in Australia: a Snapshot. Cat. No. 4828.0.55.001, ABS, Canberra.

Academy Health (2004), Glossary of Terms Commonly Used in Health Care, 2004 edition, Academy Health, Washington DC.

Acheson, D., et al. (1998), Independent Inquiry into Inequalities in Health: Report, The Stationery Office, London.

AHRQ (Agency for Healthcare Research and Quality) (2008), 2007 National Healthcare Disparities Report, US Department of Health and Human Services, Rockville, MD.

Bajekal, M. (2005), "Healthy Life Expectancy by Area Deprivation: Magnitude and Trends in England, 1994-1999”, Health Statistics Quarterly, No. 25, pp. 18-27.

Banthin et al. (2008), "Financial Burden of Health Care, 2001-2004", Health Affairs, Vol. 27, No. 1, January/February 2008, pp. 188-195.

Begg, S., et al. (2007), The Burden of Disease and Injury in Australia 2003, Australian Institute of Health and Welfare, Canberra.

Blendon, R., et al. (2002), "Inequalities in Health Care: a Five-Country Survey”, Health Affairs, Vol. 21, pp. 182-91.

Commonwealth Fund (2008), National Scorecard on U.S. Health System Performance, 2008: Chartpack, The Commonwealth Fund, New York. Available online at www.commonwealthfund.org.

Crimmins, E.M. \& Y. Saito (2001), "Trends in Healthy Life Expectancy in the United States, 1970-1990: Gender, Racial, and Educational Differences”, Social Science \& Medicine, Vol. 52, pp. 1629-1641.

CSDH (2008), Closing the Gap in a Generation: Health Equity through Action on the Social Determinants of Health. Final Report of the Commission on Social Determinants of Health, World Health Organization, Geneva.

Department of Health (2003), Tackling Health Inequalities: a Programme for Action, DoH, London. Available online at www.dh.gov.uk/assetRoot/04/01/93/62/04019362.pdf.

Department of Health (2007), Health Inequality Target Monitoring: Update to Include Data for 2006, DoH, London. Available online at www.dh.gov.uk/en/Publicationsandstatistics/Publications/PublicationsStatistics/DH_081280. 


\section{DELSA/HEA/WD/HWP(2009)2}

Department of Health (2008), Tackling Health Inequalities: 2007 Status Report on the Programme for Action, Health Inequalities Unit, DoH, London.

EU Task Force on Health Expectancies (2007), Strategic Plan of the Task Force on Health Expectancies, 2007-2010. Available online at www.tf-he.eu/Strategic_Plan_Final.pdf

European Observatory on the Social Situation (2008), Health Status and Living Conditions in an Enlarged Europe, 2007, London School of Economics and Political Science, London.

Fukuda Y., K. Nakamura \& T. Takano (2007), "Higher Mortality in Areas of Lower Socioeconomic Position Measured by a Single Index of Deprivation in Japan", Public Health, Vol. 121, pp. 163-73.

Gakidou, E. (2008), "Coverage of Cervical Cancer Screening in 57 Countries: Low Average Levels and Large Inequalities”, PLoS Medicine, Vol. 5, pp. 863-868.

Gwatkin, D.R. (2007), "Recent Trends in Research on Health Equity”, In: Global Forum Update on Research for Health Volume 4. Equitable access: Research Challenges for Health in Developing Countries, Pro-Book Publishing, London.

Harper, S. \& J. Lynch (2005), Methods for Measuring Cancer Disparities: Using Data Relevant to Healthy People 2010 Cancer-Related Objectives, National Cancer Institute, Bethesda, MD.

Health Canada (2006), Healthy Canadians - A Federal Report on Comparable Health Indicators 2006, Health Canada, Ottawa, Ontario.

Hoffman, C., et al. (2005), Medical Debt and Access to Health Care, Kaiser Commission on Medicaid and the Uninsured, September 2005, Washington.

Honjo, K., et al. (2006), "Social Class Inequalities in Self-Rated Health and their Gender and Age Group Differences in Japan”, Journal of Epidemiology, Vol. 16, pp.223-232.

Huber, M., et al. (2008), Quality in and Equality of Access to Healthcare Services, European Commission Directorate-General for Employment, Social Affairs and Equal Opportunities, Luxembourg.

Judge, K., et al. (2006), Health Inequalities: a Challenge for Europe, UK Presidency of the European Union, Central Office for Information, London.

Kambia-Chopin, B., et al. (2008), "La complémentaire santé en France en 2006 : un accès qui reste inégalitaire", Questions d'économie de la sante, No.132, IRDES, Paris.

Kawachi, I., N. Daniels \& D.E. Robinson (2005), "Health Disparities by Race and Class: why both Matter”, Health Affairs, Vol. 24, pp. 343-352.

Kawachi, I., S.V. Subramanian \& N. Almeida-Filho (2002), “A Glossary for Health Inequalities”, Journal of Epidemiology and Community Health, Vol. 56, pp. 647-652.

Khang, Y.H., et al. (2004), "Trends in Socioeconomic Health Inequalities in Korea: Use of Mortality and Morbidity Measures”, Journal of Epidemiology and Community Health, Vol. 58, pp. 308-314.

Krieger, N., et al. (2008), "The Fall and Rise of US Inequities in Premature Mortality: 1960-2002", PloS Medicine, Vol. 5(2), e46. Doi:10.1371/journal.pmed.0050046. 
Kunst, A.E. \& J.P. Mackenbach (1995), Measuring Socioeconomic Inequalities in Health, World Health Organization Regional Office for Europe, Copenhagen.

Lafortune, G., G. Balestat, and the Disability Study Expert Group Members (2007), Trends in Severe Disability among Elderly People: Assessing the Evidence in 12 OECD Countries and the Future Implications, OECD Health Working Paper No. 26, OECD, Paris.

Lopez, A.D., et al. (eds.) (2006), Global Burden of Disease and Risk Factors, The World Bank/Oxford University Press, New York.

Lozano, R., et al. (2006), "Benchmarking of Performance of Mexican States with Effective Coverage", The Lancet, Vol. 368, pp. 1729-1741.

Mackenbach, J. \& A.E. Kunst (1997), "Measuring the Magnitude of Socio-Economic Inequalities in Health: an Overview of Available Measures Illustrated with two Examples from Europe", Social Science \& Medicine, Vol. 44, pp. 757-771.

Mackenbach, J. (2006), Health Inequalities: Europe in Profile, UK Presidency of the EU 2005, London.

Mackenbach, J.P. \& EUROTHINE Project Members (2007), Tackling Health Inequalities in Europe: an Integrated Approach, EUROTHINE, Department of Public Health, University Medical Centre, Rotterdam.

Mackenbach, J.P., et al. (2008), "Socioeconomic Inequalities in Health in 22 European Countries", The New England Journal of Medicine, Vol. 358, pp. 2468-2481.

Mackenbach, J.P., W.J. Meerding \& A.E. Kunst (2007), Economic Implications of Socio-Economic Inequalities in Health in the European Union, EC Health \& Consumer Protection DirectorateGeneral, Luxembourg.

Mead, H., et al. (2008). Racial and Ethnic Disparities in U.S. Health Care: a Chartbook. The Commonwealth Fund. Available online at www.commonwealthfund.org.

Miilunpalo, S., et al. (1997), "Self-Rated Health Status as a Health Measure: the Predictive Value of SelfReported Health Status on the Use of Physician Services and on Mortality in the Working-Age Population", Journal of Clinical Epidemiology, Vol. 50, pp. 517-528.

Murphy, M., et al. (2006), "The Widening Gap in Mortality by Educational Level in the Russian Federation, 1980-2001”, American Journal of Public Health, Vol. 96, pp. 1293-1299.

Murray C.J.L., et al. (eds.) (2002). Summary Measures of Population Health: Concepts, Ethics, Measurement and Applications. WHO, Geneva.

NCHS (National Center for Health Statistics) (2007), Health, United States, 2007, NCHS, Hyattsville, MD.

NOMESCO (Nordic Medico-Statistical Committee) (2004), Health Statistics in the Nordic Countries 2002, NOMESCO, Copenhagen.

NZ MoH (New Zealand Ministry of Health) (2008), A Portrait of Health. Key Results of the 2006/07 New Zealand Health Survey, Ministry of Health, Wellington. 
O'Donnell, O., et al. (2008), Analyzing Health Equity Using Household Survey Data: A Guide to Techniques and their Implication, The World Bank, Washington DC.

OECD (2003), Transforming Disability into Ability: Policies to Promote Work and Income Security for Disabled People, OECD, Paris.

OECD (2004a), Towards High-Performing Health Systems, OECD, Paris.

OECD (2004b), Towards High-Performing Health Systems: Policy Studies, OECD, Paris.

OECD (2004c), Private Health Insurance in OECD Countries, OECD, Paris.

OECD (2007a), Health at a Glance 2007: OECD Indicators, OECD, Paris.

OECD (2007b), Society at a Glance: OECD Social Indicators, 2006 edition, OECD, Paris.

OECD (2008), The Looming Crisis in the Health Workforce: How can OECD Countries Respond?, OECD, Paris.

OECD (2009), "Analysis of Past and Projected Future Trends in Obesity in the OECD Area", OECD Health Working Paper, www.oecd.org/els/health/workingpapers, Paris, forthcoming.

Office of National Statistics (ONS) Longitudinal Study (2007), Variations Persist in Life Expectancy by Social Class, www.statistics.gov.uk/pdfdir/le1007.pdf

Or, Z., F. Jusot \& E. Yilmaz (2008), Impact of Health Care System on Socioeconomic Inequalities in Doctor Use, Working Paper DT no. 17, IRDES, Paris.

Public Health Agency of Canada (2008), The Chief Public Health Officer's Report on the State of Public Health in Canada, 2008, Public Health Agency of Canada, Ottawa.

Sanmartin, C., et al. (2004), Joint Canada/United States Survey of Health, 2002-03, Statistics Canada, Ottawa.

Schneider, M.C., et al. (2004), "Methods for Measuring Health Inequalities". Epidemiological Bulletin / PAHO 25(4): 12-14; 26(1): 5-10; 26(2): 12-15.

Schoen C., et al. (2007), “Toward Higher-Performance Health Systems: Adults' Health Care Experiences in Seven Countries, 2007”. Health Affairs, Vol. 26: w717-w734.

Schoen, C., et al. (2008), How many are Underinsured? Trends among U.S. Adults, 2003 and 2007, Health Affairs, 10 June 2008: w298.

Singh, G.K. \& M. Siahpush (2006), "Widening Socioeconomic Inequalities in US Life Expectancy, 1980-2000”, International Journal of Epidemiology, Vol. 35, pp. 969-979.

Wagstaff, A., P. Paci \& E. van Doorslaer (1991), “On the Measurement of Inequalities in Health". Social Science and Medicine, Vol. 33, pp. 545-557.

Walker, A. (2005), "Economic and Health Impacts of Narrower Health Inequalities in Australia", in J. Yfantopoulos (ed.), The Economics of Health Reforms, Atiner, Athens, pp. 263-282. 
Westert, G.P. \& H. Verkleij (eds.) (2006), Dutch health care performance report 2006, NIPHE, Bilthoven, The Netherlands.

Whitehouse, E.R. \& A. Zaidi (2008), Socio-Economic Differences in Mortality: Implications for Pensions Policy, OECD Social, Employment and Migration Working Papers No. 71, OECD, Paris.

WHO (World Health Organization) (2001), International Classification of Functioning, Disability and Health, WHO, Geneva.

WHO (2003), Health Systems Performance Assessment, WHO, Geneva.

WHO (2008), World Health Statistics 2008, WHO, Geneva.

Wilkins, R. \& C. Houle (1999), "Health Status of Children”, Health Reports, Vol. 11(3), pp. 25-34.

Wilkins, R. (2003), Socioeconomic Inequality in Health Outcomes, Health Statistics Data Users Conference 2003, Health Canada.

Xu, K., et al. (2007), "Protecting Households from Catastrophic Health Spending", Health Affairs, Vol. 26(4), pp. 972-983. 
DELSA/HEA/WD/HWP(2009)2

\section{OECD HEALTH WORKING PAPERS}

No. 42 POLICIES FOR HEALTHY AGEING: AN OVERVIEW (2009) Howard Oxley

No. 41 THE REMUNERATION OF GENERAL PRACTITIONERS AND SPECIALISTS IN 14 OECD COUNTRIES: WHAT ARE THE FACTORS EXPLAINING VARIATIONS ACROSS COUNTRIES? (2008) Rie Fujisawa and Gaetan Lafortune

No. 40 INTERNATIONAL MOBILITY OF HEALTH PROFESSIONALS AND HEALTH WORKFORCE MANAGEMENT IN CANADA: MYTHS AND REALITIES (2008) Jean-Christophe Dumont, Pascal Zurn, Jody Church and Christine Le Thi

No. 39 PHARMACEUTICAL PRICING \& REIMBURSEMENT POLICIES IN GERMANY (2008) Valérie Paris and Elizabeth Docteur

No. 38 MIGRATION OF HEALTH WORKERS: THE UK PERSPECTIVE TO 2006 (2008) James Buchan, Susanna Baldwin and Miranda Munro

No. 37 THE US PHYSICIAN FORCE: WHERE DO WE STAND? (2008) Richard A. Cooper

No. 36 UNITED STATES CASE STUDY: NURSING (2008) Linda H. Aiken and Robyn Cheung

No. 35 MISMATCHES IN THE FORMAL SECTOR, EXPANSION OF THE INFORMAL SECTOR: IMMIGRATION OF HEALTH PROFESSIONALS TO ITALY (2008) Jonathan Chaloff

No. 34 THE REMUNERATION OF GENERAL PRACTITIONERS AND SPECIALISTS IN 14 OECD COUNTRIES: WHAT ARE THE FACTORS EXPLAINING VARIATIONS ACROSS COUNTRIES? (2008) Gaetan Lafortune and Rie Fujisawa

No. 33 HEALTH WORKFORCE AND INTERNATIONAL MIGRATION: CAN NEW ZEALAND COMPETE? (2008) Pascal Zurn and Jean-Christophe Dumont

No. 32 THE PREVENTION OF LIFESTYLE-RELATED CHRONIC DISEASES: AN ECONOMIC FRAMEWORK (2008) Franco Sassi and Jeremy Hurst

No. 31 PHARMACEUTICAL PRICING AND REIMBURSEMENT POLICIES IN SLOVAKIA (2008) Zoltán Kaló, Elizabeth Docteur and Pierre Moïse

No.30 IMPROVED HEALTH SYSTEM PERFORMANCE THROUGH BETTER CARE COORDINATION (2007) Maria M. Hofmarcher, Howard Oxley and Elena Rusticelli

No. 29 HEALTH CARE QUALITY INDICATORS PROJECT 2006 DATA COLLECTION UPDATE REPORT (2007) Sandra Garcia-Armesto, Maria Luisa Gil Lapetra, Lihan Wei, Edward Kelley and the Members of the HCQI Expert Group

No. 28 PHARMACEUTICAL PRICING AND REIMBURSEMENT POLICIES IN SWEDEN (2007) Pierre Moïse and Elizabeth Docteur

No. 27 PHARMACEUTICAL PRICING AND REIMBURSEMENT POLICIES IN SWITZERLAND (2007) Valérie Paris and Elizabeth Docteur

A full list of the papers in this series can be found on the OECD website: www.oecd.org/els/health/workingpapers 


\section{RECENT RELATED OECD PUBLICATIONS:}

THE LOOMING CRISIS IN THE HEALTH WORKFORCE: CAN OECD COUNTRIES RESPOND? (2008) PHARMACEUTICAL PRICING POLICIES IN A GLOBAL MARKET (2008)

OECD HEALTH DATA 2008 (2008), available in English, French, German, Italian and Spanish on CD$\mathrm{ROM}$ (Windows XP/Vista); online version features these languages.

HEALTH AT A GLANCE: OECD INDICATORS 2007 (2007).

See www.oecd.org/health/healthataglance for more information

OECD REVIEWS OF HEALTH SYSTEMS - SWITZERLAND (2006)

LONG-TERM CARE FOR OLDER PEOPLE (2005), OECD HEALTH PROJECT SERIES

HEALTH TECHNOLOGIES AND DECISION MAKING (2005), OECD HEALTH PROJECT SERIES

OECD REVIEWS OF HEALTH CARE SYSTEMS - FINLAND (2005)

OECD REVIEWS OF HEALTH CARE SYSTEMS - MEXICO (2005)

PRIVATE HEALTH INSURANCE IN OECD COUNTRIES (2004), OECD HEALTH PROJECT SERIES

TOWARDS HIGH-PERFORMING HEALTH SYSTEMS - POLICY STUDIES (2004), OECD HEALTH PROJECT SERIES

TOWARDS HIGH-PERFORMING HEALTH SYSTEMS (2004), OECD HEALTH PROJECT SERIES

OECD REVIEWS OF HEALTH CARE SYSTEMS - KOREA (2003)

A DISEASE-BASED COMPARISON OF HEALTH SYSTEMS: WHAT IS BEST AND AT WHAT COST? (2003)

MEASURING UP: IMPROVING HEALTH SYSTEMS PERFORMANCE IN OECD COUNTRIES (2002)

A SYSTEM OF HEALTH ACCOUNTS (2000)

For a full list, consult the OECD On-Line Bookstore at www.oecd.org, or write for a free written catalogue to the following address:

OECD Publications Service

2, rue André-Pascal, 75775 PARIS CEDEX 16

or to the OECD Distributor in your country 